\title{
Tumor reversion: a dream or a reality
}

\author{
Avantika Tripathi $^{1+}$, Anjali Kashyap $^{2 \dagger}$, Greesham Tripathi ${ }^{1 \dagger}$, Joni Yadav ${ }^{3}$, Rakhi Bibban $^{3}$, Nikita Aggarwal $^{3}$, \\ Kulbhushan Thakur ${ }^{3}$, Arun Chhokar ${ }^{3}$, Mohit Jadli $^{3}$, Ashok Kumar Sah ${ }^{4,5}$, Yeshvandra Verma ${ }^{6}$, Hatem Zayed ${ }^{7}$, \\ Amjad Husain ${ }^{8,9}$, Alok Chandra Bharti ${ }^{3^{*}}$ and Manoj Kumar Kashyap ${ }^{1,3^{*}}$ (i)
}

\begin{abstract}
Reversion of tumor to a normal differentiated cell once considered a dream is now at the brink of becoming a reality. Different layers of molecules/events such as microRNAs, transcription factors, alternative RNA splicing, posttranscriptional, post-translational modifications, availability of proteomics, genomics editing tools, and chemical biology approaches gave hope to manipulation of cancer cells reversion to a normal cell phenotype as evidences are subtle but definitive. Regardless of the advancement, there is a long way to go, as customized techniques are required to be fine-tuned with precision to attain more insights into tumor reversion. Tumor regression models using available genome-editing methods, followed by in vitro and in vivo proteomics profiling techniques show early evidence. This review summarizes tumor reversion developments, present issues, and unaddressed challenges that remained in the uncharted territory to modulate cellular machinery for tumor reversion towards therapeutic purposes successfully. Ongoing research reaffirms the potential promises of understanding the mechanism of tumor reversion and required refinement that is warranted in vitro and in vivo models of tumor reversion, and the potential translation of these into cancer therapy. Furthermore, therapeutic compounds were reported to induce phenotypic changes in cancer cells into normal cells, which will contribute in understanding the mechanism of tumor reversion. Altogether, the efforts collectively suggest that tumor reversion will likely reveal a new wave of therapeutic discoveries that will significantly impact clinical practice in cancer therapy.
\end{abstract}

Keywords: Tumor reversion, TCTP1, SIAH1, Phenotype reversion, Revertant, PTMs

\section{Introduction}

Cancer is a complex genetic disease that can be either solid or hematological type. The GLOBOCAN report in 2018 estimated that the total number of new cases and death is predicted to be 18.1 and 9.6 million, respectively [1]. Uncontrolled proliferation and loss of cellular and molecular architecture are typical characteristics of cancers [2]. For many years, the somatic mutation theory (SMT) was used as the basis for explaining the cause

\footnotetext{
* Correspondence: alokchandrab@yahoo.com; mkkashyap@ggn.amity.edu ${ }^{\dagger}$ Avantika Tripathi, Anjali Kashyap and Greesham Tripathi contributed equally to this work

${ }^{3}$ Department of Zoology, Molecular Oncology Laboratory, University of Delhi (North Campus), New Delhi 110007, India

${ }^{1}$ Amity Stem Cell Institute, Amity Medical School, Amity University Haryana, Panchgaon, Haryana, Manesar (Gurugram) -122413, India

Full list of author information is available at the end of the article
}

behind carcinogenesis. SMT mostly relates to noninheritance cancers, including 90-95\% of all cancer types. In 1914, Boveri was the first person to introduce the SMT first explanation, which showed that for changing the cell's phenotype, the genotype had to be changed [3]. Over time, it has been claimed that a single somatic cell contains multiple DNA mutations in cancer, indicating that cancers are monoclonal [4]. Their central premise was (1) cancer is a defect of the control of cell proliferation, and (2) quiescent state is the default state for metazoan cells [5]. Later, another theory came into the picture called "The tissue organization field theory of carcinogenesis" (TOFT), which considers DNA mutations not the cause of cancer, as in SMT, but as the effect [6]. Towards the end of the nineteenth century, Bold, Cohnheim, and Ribbert provided theory based on

(c) The Author(s). 2021 Open Access This article is licensed under a Creative Commons Attribution 4.0 International License, which permits use, sharing, adaptation, distribution and reproduction in any medium or format, as long as you give appropriate credit to the original author(s) and the source, provide a link to the Creative Commons licence, and indicate if changes were made. The images or other third party material in this article are included in the article's Creative Commons licence, unless indicated otherwise in a credit line to the material. If material is not included in the article's Creative Commons licence and your intended use is not permitted by statutory regulation or exceeds the permitted use, you will need to obtain permission directly from the copyright holder. To view a copy of this licence, visit http://creativecommons.org/licenses/by/4.0/ The Creative Commons Public Domain Dedication waiver (http://creativecommons.org/publicdomain/zero/1.0/) applies to the data made available in this article, unless otherwise stated in a credit line to the data. 
the interactions between tissues; cancer produced in embryonic residues and epithelial cells do not contain any special proliferative power, but that their proliferation results from being freed from the restrictions imposed by normal tissue organization. Their basic premises are: (I) Motility and proliferation are the default cellular states, (II) Carcinogenesis, and neoplasia are the outcome of the tissue architecture defects [7]. In the initial phase, carcinogens will disrupt the parenchyma's normal interactions and an organ's stroma. It appears as the primary target (The morphological field of developing organisms). Neoplastic cells are reprogrammed to work as normal cells in "normal tissue". Carcinogens initially disrupt normal interactions among parenchymal and stromal cells of an organ (an equivalent of the "morphogenetic fields" of a growing organism). An emergent (supracellular) phenomenon is involved in the cause of Carcinogenesis and neoplasia. According to TOFT, pro-carcinogenic agents disrupt and interfere with the normal tissue architecture, and lead to the destruction of cell-to-cell signaling and conciliate the genomic integrity [8].

A large number of switches such as chromosomal instability, loss of heterozygosity, accumulation of mutations, DNA methylation, and intron retention (particularly in TSGs), escape of the immunosurveillance of the immune system, aberrations in metabolism, defect in DNA machinery, uncontrolled cell division, neo-angiogenesis, dysregulation of post-transcriptional modifications \& post-translational modifications (PTMs), a nexus of the tumor microenvironment, and changes in the extracellular matrix composition, are collectively responsible for the transformation of normal cells into the malignant form [9].

The different output or so-called differentially-regulated molecules between cancers vs. normal cells/tissues have been used as potential anti-cancer therapy targets for different malignancies [10]. Targeting different types of tumors had been the center of attraction using other chemical probes, antibodies, or mimetic to see an impact on the tumor volume and or survival of the animals and the patients. In recent years, changing cancer cell's profile into normal (also called phenotype reversion or tumor reversion) also received a lot of attention.

The process of tumor reversion was first described in the twentieth century while studying ovarian teratomas. Through embryonic differentiation, tumor cells could rise to normal cells [11]. Interestingly, SV40 or polyoma infected NIH/3T3 cells were enriched, and those possessed enhancements of improved contact inhibition, and sensitivity, along with attrition in the capacity to produce a tumor. These variants of the parental cell lines are described as "revertants". The tissues of embryonic origin reverted cancerous cells into normal using the guidance cues from the normal microenvironment [2].
Reversion of tumor cells involves the regeneration of the whole or as a part of the standard growth control mechanisms, which disappeared in the malignant cells. Still, tumor progression has been a serious concern as it poses severe challenges to biomedical scientists and clinicians worldwide. Several therapeutic agents, including standard of care (SOC) drugs, have been used to treat cancer patients to inhibit/stop the tumor progression. In contrast to tumor progression, the phenomenon of tumor reversion is less studied. Tumor reversion is a biological process involving reprogramming of tumor cells that overcome the aberrancies such as loss of heterozygosity, mutations, inactivation of TSGs, hyperactivation of oncogenes, and eventually leading to tumor phenotype conversion into normal. The in vitro and in vivo approaches are used to manipulate the cellular machinery for correcting the behavior of tumor cells in different malignancies [2].

Reports are showing that the morphogenetic fields can guide tissue to behave differently. When applied on tumor cells growing in the vicinity of normal tissues as embryonic through cellular reprogramming, it could revert into a normal phenotype [12]. Several studies successfully used molecular reprogramming for reverting the tumor phenotype [12-14]. Recently, similar experimental approaches applied to several different malignancies, including leukemia, [15] breast cancer, [15] prostate cancer, [16] ovarian cancer, [17] and liver cancer, [18] to study tumor reversion.

The high-throughput techniques such as DNA or oligonucleotide microarrays were used to identify differentially regulated genes between normal vs. cancerous tissues. This technology provided significant insights on significantly dysregulated genes and helped to understand the changes in an individual or a set of genes in different stages of the tumor.

Malignant cells originate from the normal cells, so the major challenge is to reminiscence the molecular pathophysiology behind tumor reversion, which has been overlooked largely due to limited researcher interest and involvement in this area of research. Still, a significant number of evidence, based on the observations from different studies showed that tumor microenvironment, post-transcriptional modifications, PTMs, chemical compounds including anti-sense oligonucleotides (ASOs), and miRs raise the possibility that further advancement in this field could make it possible to use tumor reversion as an alternative strategy or synergistically along with currently available SOCs.

In this review, we discussed current updates in the field of tumor reversion including currently available in vitro, in vivo, and 3D culture-based models to study tumor reversion, different molecular events involved, compounds exploited for tumor reversion, and above all 
the challenges along with critical scientific thoughts to implement multi-omics [19], and the current state-ofthe-art technologies to delineate the molecular process of tumor reversion.

\section{Molecules involved in tumor reversion}

Several molecular processes and molecules were reported to be involved in tumor reversion (Table 1, and Fig. 1); still, only a selected group of researchers focused on dissecting the complicated biological process of tumor reversion globally. The protein architecture of different molecules involved in tumor reversion is provided in Fig. 2. Some of these critical molecules involved in tumor reversion are:

\section{Translationally controlled tumor protein 1 (TCTP1)}

In humans, the Translationally Controlled Tumor Protein (TCTP) is encoded by the TPT1 gene, which is located on 13q12-q1413. It consists of six exons and five introns [32]. TCTP is a secretory calcium-binding protein whose expression has been reported in biological fluids such as saliva and semen. TPT1 is a direct target gene of TP53. The conditional KO mice of TPT1 showed retardation in the development of the brain and leads to death in the perinatal stage. The expression of TPT1 across different normal human samples has been shown in Fig. 3. The TPT1 mRNA expression profile clearly shows that at least a minimum count of 97.21 RPKM was present across all the normal organs. The proteinprotein interactions (PPIs) of TCTP proteins are provided in Supplementary Table-1.

PPIs can be identified using phage display, immunoprecipitation, and Yeast two-hybrid $(\mathrm{Y} 2 \mathrm{H})$ techniques. Over 200 PPIs involve TCTP protein; as evident from different PPI analysis platforms like $\mathrm{Y} 2 \mathrm{H}$, affinity captures mass spectrometry, Affinity CaptureLuminescence, or Affinity Capture-Western [33].

$\mathrm{Y} 2 \mathrm{H}$ is a molecular technique that is used for the identification of PPIs especially the physical interactions $[34,35]$. The functioning of the cellular machinery depends on the physical interactions between domains of several transcription factors. These domains are structurally and functionally different: DNA binding domain (BD), and DNA activation domain (AD). Among these, $\mathrm{BD}$ binds to the DNA sequence upstream of the reporter gene, and $\mathrm{AD}$ stimulates the reporter gene expression. The protein in questions (Query) fuses with $\mathrm{BD}$ and known as BAIT, the library of proteins fuse with $\mathrm{AD}$ and known as prey [36]. $\mathrm{Y} 2 \mathrm{H}$ takes advantage of the fact that gene transcription requires the binding of two domains of a transcriptional activator protein. These domains are called the DNA-binding domain and the activator domain. For two-hybrid analysis, each domain is fused to one of two candidate interacting proteins. If these proteins interact then a functional transcriptional activator is formed. This triggers the transcription of a reporter gene, which gives an observable change in phenotype. In $\mathrm{Y} 2 \mathrm{H}$, a reporter expressed if there is an interaction between two proteins. In $\mathrm{Y} 2 \mathrm{H}$, one can screen for interacting partners without purifying the protein. There are some drawbacks of $\mathrm{Y} 2 \mathrm{H}$ as well including the limitations of testing for pairwise interactions only. $\mathrm{Y} 2 \mathrm{H}$ is prone to a high false-positive rate as well. Some of the critical PPIs were between TCTP and MCL1, TCTP and SPP1, \& TCTP and BCL2L1 as listed in Supplementary Table 1.

Dysregulation of TCTP in breast cancer led to the restructuring of the tumor and initiation of making duct-like structures giving the mnemonic impression of normal breast tissue [15]. Overexpression of the TCTP has been associated with a poor prognosis in ovarian cancer. The siRNA knockdown of the TPT1 gene showed retarded growth of the ovarian carcinoma cell lines in vitro suggesting its role in cell proliferation [37].

\section{SIAH E3 ubiquitin protein ligase 1 (SIAH1)}

An E3 ubiquitin-protein ligase that is encoded by the gene SIAH1, [32] involved in ubiquitination and degradation of specific proteins via proteasome through an interaction of SIAH1 with NUMB. Mutations in SIAH1 inhibit the $\beta$ catenin degradation, and these mutations have been reported in gastric cancer samples as well [38]. Not only SIAH1 but also its homologs (Siah1 \& Siah2) interacts with DCC (deleted in colorectal cancer) and subjects it to proteolysis through the ubiquitin-proteasome pathway [39]. Inactivation of SIAH1 is associated with hepatocellular carcinoma (HCC) tumor progression [40]. Overexpression of SIAH1 in colorectal cancer (CRC) led to the suppression of cellular proliferation and invasion of malignant cells. In contrast, SIAH1 knockdown promotes both proliferation as well as invasion of CRC cells [41]. Overexpression of SIAH1 in U937 cells not only induce apoptosis but also led to tumor reversion [20].

\section{Presenilin (PSEN1)}

Human presenilin protein encoded by the PSEN1 gene, which is located on locus 14q24.3. This protein possesses one transmembrane domain, as well as one PSN domain [32]. PSEN1 is an important $\gamma$-secretase complex member that plays a crucial role in the NOTCH signaling pathway. An upregulation and over-amplification of the PSEN1 were observed in cancerous tissues and cell lines of gastric origin. It was positively correlated with lymph node (LN) metastasis and poor survival rate in gastric cancer patients [42]. An ASO blocking PSEN1 that was used in leukemic cell lines (K562 and U937) induces apoptosis, and reverts the tumor phenotype in the cell lines as well as in vivo in the SCID mouse model [20]. 


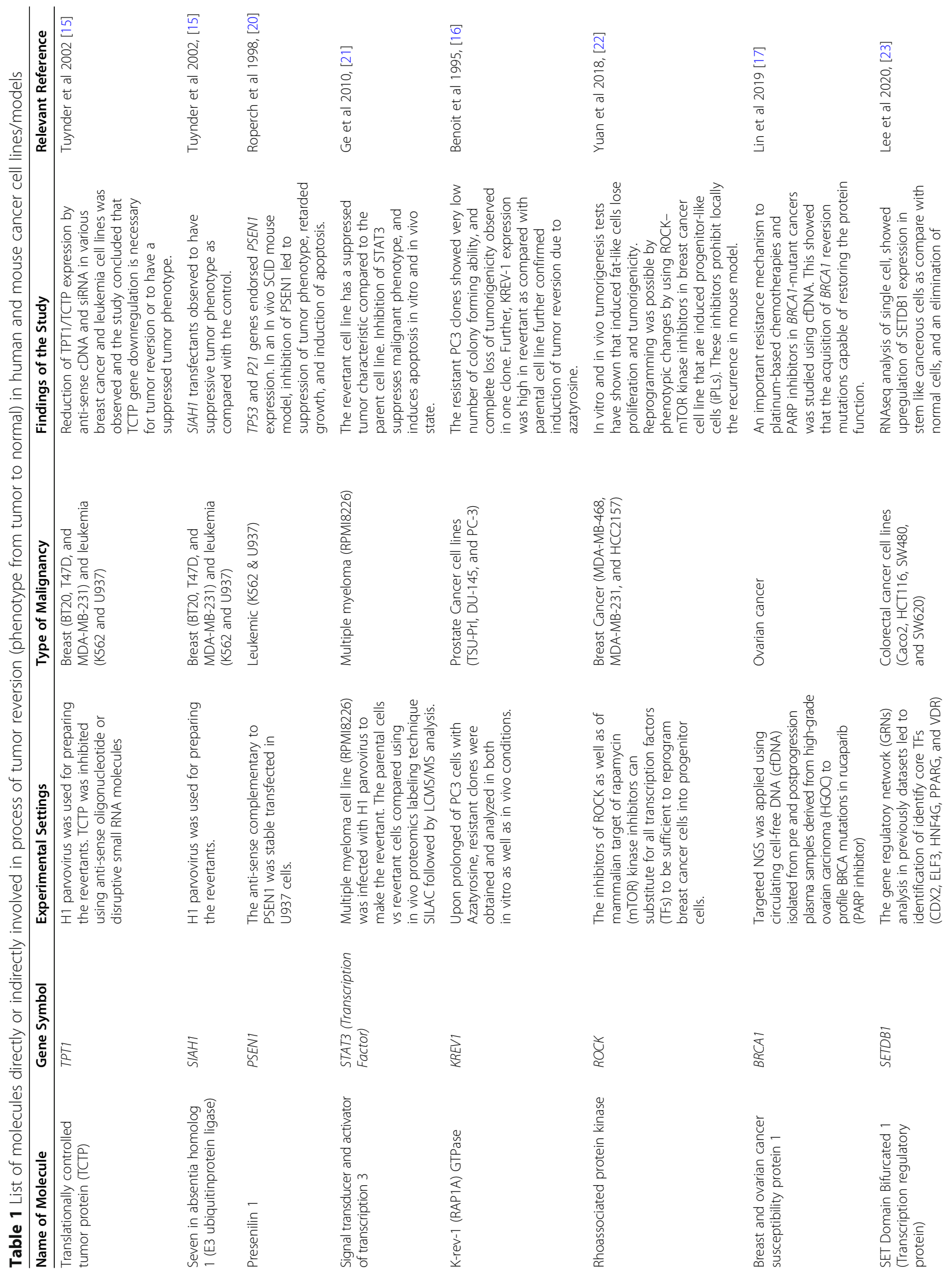




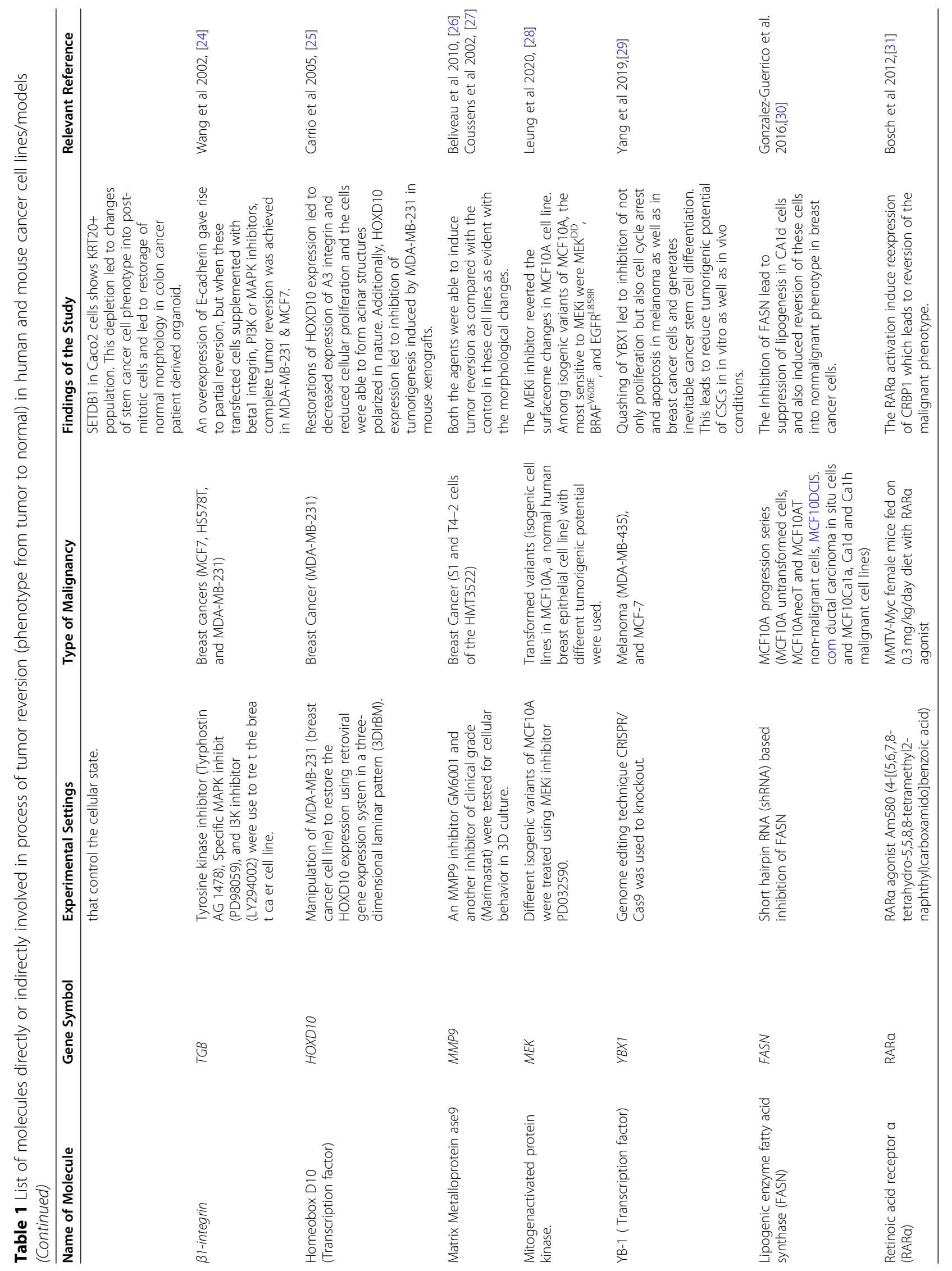




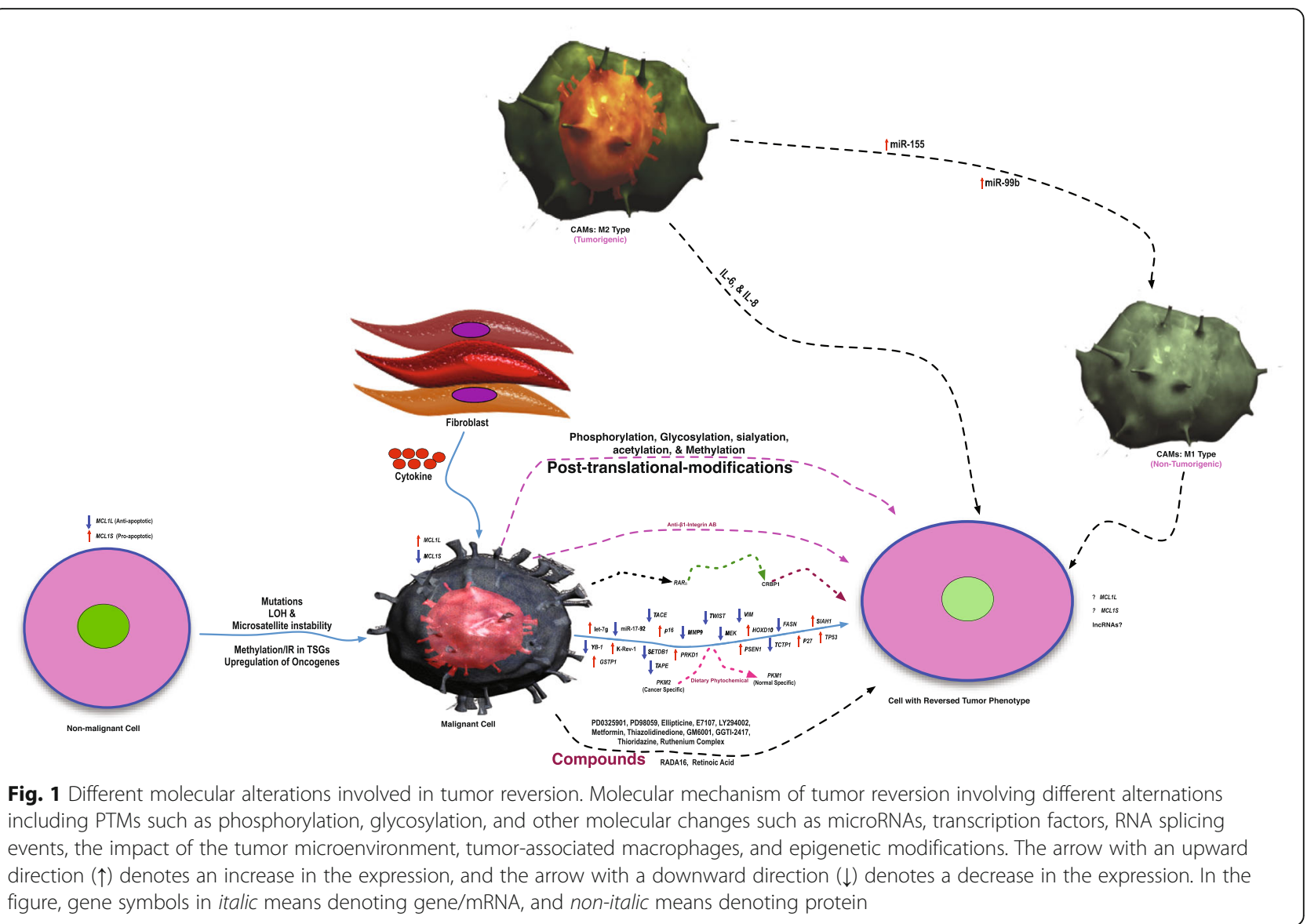

\section{Tumor suppressor activated pathway 6 (TSAP6)}

The official gene symbol for the tumor suppressor activated pathway 6 (TSAP6) is STEAP3 that is mapped to $2 \mathrm{q} 14.2$. It is a cell cycle control protein, which possesses six transmembrane domains. Due to its active role in tumor reversion/suppression, it was given the name TSAP6 [10]. The blockage of TSAP6 using ASO or siRNA-mediated knockdown induces cell death in TP53 dependent manner [43]. An exosome discharge model came into existence due to the exosome secretory nature of TSAP6 [44]. The TSAP6 KO was not efficient in making exosomes. TSAP6 transnationally controls the secretion of TCTP, and sometimes works as a detoxifier for the cells. $\mathrm{Y} 2 \mathrm{H}$ assay revealed that TSAP binds with TCTP. Following TP53 activated, TSAP6 gets active and behaves as a tumor suppressor, and it was along with the TPT1 gene found in the tumor revertants derived from U937 cell lines suggests that it is also an important gene involved in the process of tumor reversion [13].

\section{KREV-1}

The official gene symbol for $K R E V-1$ is $R A P 1 A$ (Ras-related protein Rap-1A). RAP1A gene is located on $1 \mathrm{p} 13.3$.
The RAP1A encodes the KREV-1 protein in humans. This protein is a GTPase. Overexpression of KREV-1 protein was found to be associated with different malignancies. Through AKT signaling, RAP1A promotes metastasis in esophageal squamous cell carcinoma (ESCC), [45] and an aggressive phenotype in colorectal cancer through PTEN/FOXO3/CCND1 pathway [46]. The revertants were obtained after prolonged exposure of prostate cancer cell lines with Azatyrosine. The revertants obtained were with elevated expression of KREV-1 showed low colony formation and no tumorigenicity in the mouse model; this suggests the role of $K R E V-1$ in tumor reversion [16].

MYC

MYC proto-oncogene, or bHLH transcription factor is encoded by the gene MYC (alias C-Myc) that is located on $8 \mathrm{q} 24.21 . M Y C$ is a transcription factor that regulates a large number of genes essential for the progression of the $\mathrm{G} 1$ to $\mathrm{S}$ phase of the cell cycle. $M Y C$ is known to be associated with tumor progression in different cancers, including cervical, oral, and multiple myeloma [47-51]. MYC is very crucial for angiogenesis which is a key factor for the aggressive behavior of a tumor [51]. Tumor 


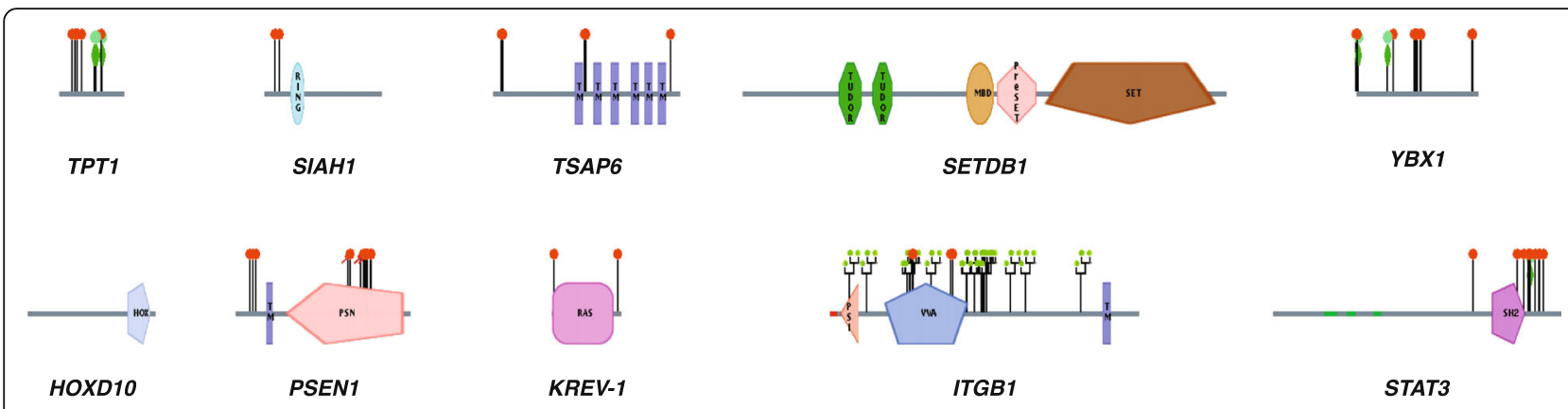

Fig. 2 Protein Architecture of different proteins involved in the tumor reversion. Using the human protein reference database, the architecture of proteins involved in tumor reversion or phenotypic tumor reversion has been shown include TPT1, SIAH1, TSAP6, SETDB1, YBX1, HOXD10, PSEN1, KREV-1, ITGB1, and STAT3

regression has been an important event observed in the large number of transgenic mouse models. The crucial question about the fate of cells remains unclear i.e. if they change to a non-malignant, malignant, or quiescent state. MYC inhibition leads to complete tumor elimination in lymphoma and osteosarcoma models [52, 53]. MYC inhibition reverses tumors into a normal or dormant state of cells. This puzzle was investigated in osteosarcoma and lymphoma where blockade of MYC successfully remove the complete tumor. Though intriguing, tumor cells derived from MYC-induced breast and hepatocellular carcinoma were reverted into a dormant state. Furthermore, dormant cells upon MYC reactivation again reverted to tumor state $[54,55]$. This indicates the compulsiveness of MYC for the cells. MYC inactivation led to tumor reversion in different tumors [56].
As low as two-fold decrease in MYC expression can lead to tumor reversion in a cell-specific manner [57].

Tumor reversion was also observed upon MYC suppression in several malignancies, including $\mathrm{T}$ and $\mathrm{B}$ cell leukemia and lymphoma, squamous cell, and mesenchymal cancers [52, 53, 58, 59].

\section{Role of microenvironment and associated factors in tumor reversion}

Interaction between tumor and microenvironment entities plays a crucial role in determining the behavior of the tumor. Apart from malignant cells, the TME cellular components are immune cells, the vasculature of the tumor, and the lymphatic endothelial cells, fibroblasts, adipocytes, and pericytes. The term "TME"

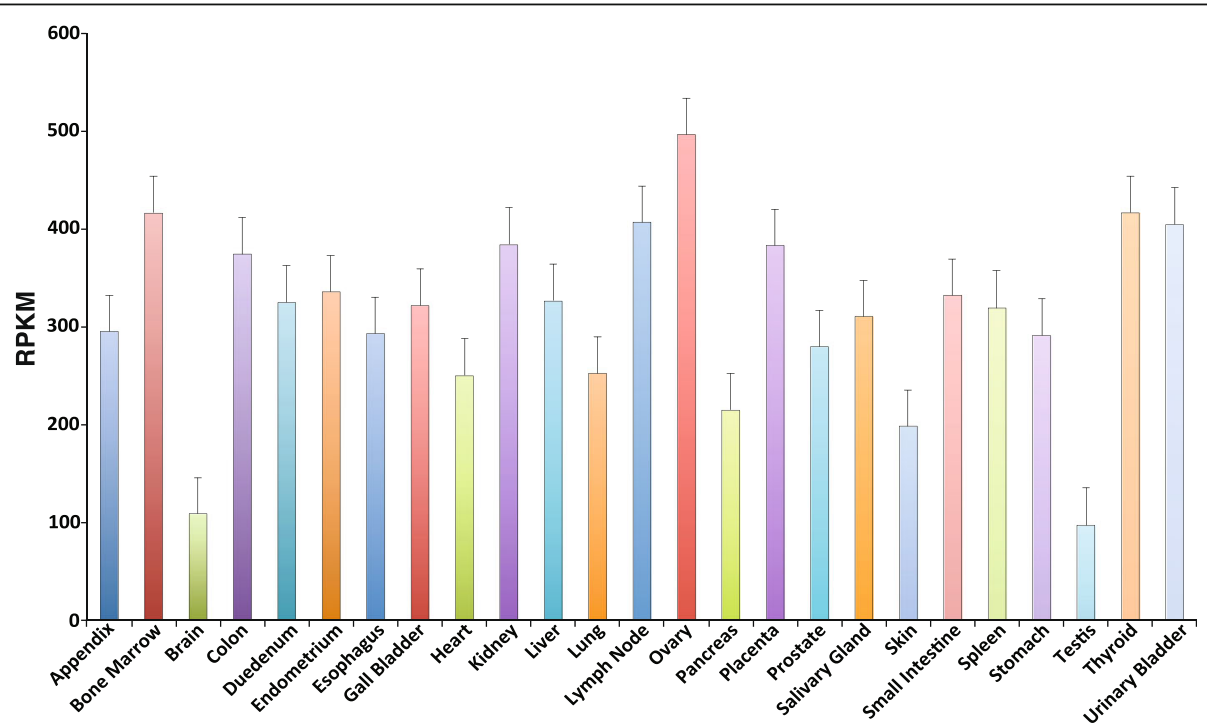

Fig. 3 The mRNA expression of TPT1 across different normal human tissues. An mRNA expression of the TPT1 gene has been shown across all possible normal human tissue samples including (from left $\rightarrow$ to right) appendix, bone marrow, brain, colon, duodenum, endometrium, esophagus, gall bladder, heart, kidney, liver, lung, lymph node (LN), ovary, pancreas, placenta, prostate, salivary gland, skin, small intestine, spleen, stomach, testis, thyroid, and urinary bladder. The value of the expression is shown in form of Reads Per Kilobase of transcript per million mapped reads (RPKM), which are the normalized unit for denoting transcript expression 
sometimes is confusing giving the impression that only cancerous cells are involved. In contrast, non-cancerous cells are involved and those are essential for different stages including tumorigenesis, progression, and metastasis. Additionally, secretory proteins and blood vessels are also involved [60, 61]. Stromal cells and the extracellular matrix (ECM) constitute the structure of the TME. ECM consists of proteoglycans, fibrous proteins including collagen, fibronectin, laminin, tenascin, and hyaluronic acid [62]. TME has been reported in a large number of studies to play a very crucial role in tumor maintenance and progression. Furthermore, TME contributes to tumor reversion [63]. Tumorassociated macrophages (TAMs) are the cells found in TME and these are associated with the microvessel density of the tumor tissues. TAMs are mainly of two types based on their pro-tumorigenic (M2/Th2-activated) or anti-tumorigenic behavior (M1/Th1-activated). The balance between M1 and M2 decides the kind of phenotypic behavior expected in a tumor. The evolution of the TME depends on the stage and type of the cancer. TME can revert the anti-tumor program and favor a switch of infiltrated macrophages into an M2 phenotype with pro-tumor and immune-suppressive functions [64]. TAM-specific inactivation of IKK $\beta$, which disrupts NF- $\mathrm{kB}$ signaling resulted in an M2-to-M1 switch, recruitment of natural killer cells, and subsequent tumor regression in an ovarian cancer model [65].

The M2 subtype of TAMs is crucial in creating an immunosuppressive TME because these macrophages can secrete cytokines, growth factors, and chemokines, that inhibit the immune checkpoints in the T-cells. This property has been exploited for reverting the tumor in several studies. TAMs are important in polarizing the phenotype of a tumor. The macrophage depolarization of an M2 phenotype via CSF-1R inhibition led to tumor regression of established high-grade gliomas [66].

The embryonic microenvironment plays an important role in reprogramming metastatic tumor cells [67]. The nodal inhibitor showed no effect in tumors treated alone than cultured within the vicinity of human embryonic stem cells (hESC). The latter not only responded but also the cells started initiated to show features alike normal phenotype [68].

The microenvironment plays an essential role in regulating tumor growth [2]. The cultured breast cancer cells treated with an antibody blocking integrin showed features like normal cells e.g. ductal structures looking alike normal breast epithelial cells [69].

It is also well established that the tumor progression in solid tumors rely on new vasculature formation through angiogenesis. Experimental evidences reveal that the most human tumors arise without angiogenic activity and remain dormant and viable as microscopic lesions for extended periods. The angiogenic phenotype in human tumors can also spontaneously revert to the non-angiogenic phenotype in the small population $(\sim 4-6 \%)$ of tumor cells. If the rate of reversion to the non-angiogenic phenotype can be increased therapeutically, this could lead to a novel anticancer strategy through tumor reversion.

\section{Alternative RNA splicing and tumor reversion}

The process of RNA splicing is responsible for bringing diversity at transcript as well as protein levels. The RNA splicing machinery "spliceosome" orchestrates this process. RNA splicing has been reported to play a crucial role in different biological mechanisms essential for cancer progression, metastasis, tumor-microenvironment interaction, drug resistance, epithelial-mesenchymal transition (EMT), and mesenchymal-epithelial transition (MET), in tumor reversion. A peculiar characteristic of cancer cells is aberrant RNA splicing, which forces the cells to reorganize their specific RNA spliced forms required for that particular stress/ cancer and contributing to the tumorigenesis. Cancerspecific AS events have been documented that are responsible for tumor progression as well [70]. The spliceosome complex controls the RNA splicing events. There are several cases where RNA splicing able to induce/modulate tumor reversion. Serine/arginine-rich splicing factor 1 (SRSF1) gene is also known as SF2/ASF. SRSF1 upregulation has been reported in breast cancer. Notably, several endogenous splicing targets of SF2/ASF, including novel oncogenic isoform of the mTOR substrate, S6K1, are essential for SF2/ASF-mediated transformation. Also, RNA interference (RNAi) of SF2/ASF or the oncogenic S6K1 isoform resulted in the reversion of the transformed phenotype [71]. A number of macrolide splicing modulators (SPLMs) have been used for modulation of RNA splicing for anti-cancer activities. These SPLMs not only affect the total protein levels but also the PTMs (including but not limited to, phosphorylation, and glycosylation). Indole derivatives IDC92 have been tested for modulation of RNA splicing in breast cancer where these were able to show anti-proliferative activities in the cancer cells, and not only reverse the abnormal splicing form $\triangle \mathrm{RON}$ (of protooncogene $\mathrm{RON}$ ), but also the invasive phenotype of the breast cancer cells without altering the splicing of other targets like SF2/ASF [71].

In cancer cells, the pyruvate kinase muscle isoenzyme (PKM) plays a significant role in cancer cell metabolism to adapt to a new ambience. In a study on head \& neck cancer cells, treatment with dietary-phytochemical able to induce reversion of PKM2 (cancer-specific isoform) into PKM1 (normal specific) isoform and also lead to inhibition of H\&N cancer [72].

In the case of chronic lymphocytic leukemia (CLL), macrolide SPLMs like pladienolide-B and FD-895 were able to modulate the myeloid cell leukemia factor 1 (MCL1) gene transcript isoforms (larger-MCL1L: largeranti-apoptotic, and shorter, MCLS: pro-apoptotic) after treatment in CLL-B cells. This impact was preferentially 
in CLL-B cells only [73]. Even derivatives of FD-895 were also able to recapitulate the same properties in primary CLL-B cells and other leukemia and lymphoma cell lines [74].

\section{Non-coding RNAs and their role in tumor reversion}

In addition to high-throughput techniques like RNAseq have shown that the human transcriptome is complex and its regulation is controlled through different developmental stages [75]. The ncRNAs are functional as those are able to transcribe but unable to translate into protein. The ncRNAs primarily are of two types: small ncRNAs $(<200$ nucleotide length) and long ncRNAs (lncRNAs, > 200 nucleotide length) [76]. Among sncRNAs are regulatory RNAs like microRNAs (miRNAs or miRs), rRNA, tRNA, \& splicing RNAs [77, 78].

The miRs are single-stranded, endogenously occurring small RNAs with varying lengths from 20 to 23 nucleotides post-transcriptionally regulate gene expression [79]. An interaction via complementary base pairing between miR, and mRNA is essential for target mRNA's translation or stability. These are involved in regulating the gene expression by integrating with the RNAinduced silencing complex (RISC). Further, miRs can suppress the translation or degradation by binding to the 3 '-untranslated region (3'-UTR) of the mRNA [77]. In recent years, a different research group reported that the target of miRs is the $3^{\prime}$-UTR, and in some cases miRs target $5^{\prime}$-UTRs as well [80, 81].

\section{Role of miRs in tumor reversion}

In most studies, miRs or microRNAs have been reported in tumor progression. Still, a few studies also reported the role of miRs in tumor suppression, and rare cases in reverting the tumor phenotype into normal (tumor reversion). Among miRs, miR-155 is a known macrophage polarization modulator. In the TAMs derived from the bone marrow-derived macrophages (BMDMs), overexpression of miR-155 was able to polarize tumorigenic M2 macrophages (anti-inflammatory profile) into inducing anti-tumor macrophage M1 ('classic' pro-inflammatory phenotype). The miR-155 expression was upregulated in M1 polarized macrophages types by $>120$-fold suggesting its crucial role in reversing a tumorigenic to antitumorigenic phenotype [82]. Further, overexpression of miR-99b in TAMs educated them towards the anti-cancer phenotype that led to hindrance in the HCC and LLC growth and further improved immune surveillance [83].

The tumor could serve as a good target for inducing the tumor regression by targeting the genes using miRs or anti-miRs in cancers with altered protein-forming genes [84]. The miR-26a targeting c-MYC mRNA induced tumor regression in HCC [85]. Another miR let-7 was originally discovered first in nematodes has been reported in different malignancies. The let-7 group miRs are essential for apoptosis, cellular proliferation, and invasion of cancerous cells. The let- $7 \mathrm{miR}$ is essential in maintaining the state of differentiation in somatic cells. Ectopic overexpression of let-7 $\mathrm{g}$ in human ovarian cancer cell lines reduce cell's growth, induces arrest of the G0/G1 phase of the cell cycle, reduces EMT and cell motility [86]. The reduced let-7 level was associated with regression in the mesenchymal phenotype and shorter survival. Higher let-7 expression and higher EMT could not form a detectable tumor, but in contrast, a lower let7 level and lower EMT led to the tumorigenic phenotype [87].

The miRs have been associated with HCC, and a large number of differentially regulated miRs have been reported between HCC vs normal. Among these, miR-21 and miR-17-92 were subtly upregulated in HCC as compared with the normal tissue sample. The anti-sense oligonucleotide-mediated inhibition of miR-17-92 and miR-21 induced a significant reduction in cellular proliferation, which was $\sim 55$ and $21 \%$, respectively. Additionally, considerable retardation was observed in the G1 phase of cell cycle in HepG2 cells. The knockdown of miR-17-92 also decreased the anchorage-independent growth significantly in HepG2 cells. Overall, this evidence shows that miR-17-92 knockdown led to partial phenotypic tumor reversion and suggests its involvement in tumor reversion [88].

The miR-200 family consists of very important miRs, including miR-200a, miR-200b, miR-200c, miR-141, and miR-429. The ZEB (zinc-finger enhancer-binding protein) / miR-200 response loop is a cellular plastic cell engine for the development and diagnosis. In particular, it can advance cancer toward metastasis by controlling the cellular stem cell culture. Interestingly, miR-200c induced overexpression overturns chemotherapy and EGFRmediated resistance in reproductive cancer [89]. The miR200c possesses pro-apoptotic properties and targets FAP1 (an apoptosis inhibitor) and makes the cancer cells perceptive to apoptosis [90].

A systematic RNA screening led to the identification of miRs playing a key role backed by MET in the starting phase of phenotype reversion. These steps are directly dependent on miR-205 and the cluster of miR-200 family. The ectopic expression of the miR-200 family and miR-205 can revert the mesenchymal to epithelial transition (MET) in mesenchymal cells. In concordance with their EMT role, these miRs were lost in mesenchymal phenotype bearing invasive breast cancer cell lines [91].

Another important type of ncRNAs subtype is lncRNAs. We carried out an extensive search on it but unable to find even a single study reporting role of lncRNAs in tumor reversion. This is also largely possible because there is not even a single study focused on 
either deploying lncRNA or RNAseq profiling as both of these high-throughput techniques can capture the lncRNA profile between normal vs cancer groups.

\section{Transcription factors and tumor reversion}

Alternative RNA splicing is the basis for bringing the diversity in the transcriptome and eventually in the proteome as well. An optimum balance between isoforms is critical for the normal biological functioning of different organisms. Besides AS, transcription factors (TFs) play a significant role in the regulation of different malignancies [92]. The TFs are involved in tumor regulation, proliferation, progression, and metastasis and play a significant role in regulating changing the phenotype from cancer to normal. Some of the TFs that have been reported in tumor phenotypic reversions are discussed here.

\section{Homeobox D10 (HOXD10)}

The homeobox D10 gene (HOXD10) belongs to the HOX family of genes that are important for various processes related to development [93]. HOXD10 has been reported to be involved in several different malignancies [94]. An elevated expression of HOXD10 led to tumor quiescence; it also has been reported as a TSG in pancreatic and cholangiocarcinoma [95]. HOXD10 induces reversion of tumor phenotype in $3 \mathrm{D}$ culture conditions in breast cancer [25].

\section{Signal transducer and activator of transcription 3 (STAT3)}

STAT3 is an important transcription factor that consists of one SH2 domain and 3 CC motifs [32]. It is involved in various diseases, including cancers. It plays a pivotal role in inflammation, normal growth, and development. Under pathological conditions, its aberrant activation leads to growth, progression, angiogenesis, chemoresistance, and tumor cell's survival [96]. Blockage/inhibition of STAT3 showed a profound anti-cancer effect in vitro as well as in vivo conditions [97-99]. Targeting STAT3 by pharmacological or genetic means led to tumor reversion as well [100].

\section{Post-translational modifications in tumor reversion}

PTMs are enzymatic modifications in proteins and play a very significant role in cell signaling. All the PTMs relevant to tumor reversion are summarized and discussed in Table 2. PTMs are the outcome of specific but local physiological or stressed/disease states. PTMs are critical events, which can alter the conformation of the protein, their stability, and diversity. PTMs are very crucial for biological processes, cellular proliferation, development, differentiation, diseases/tumor progression, and drug resistance [114]. PTMs are vital for dissecting the mechanistic angle of the biology behind tumor reversion, as we observed only a handful of PTMs concerning tumor reversion. Among PTMs, phosphorylation (p) had been a winner as it has been extensively studied for proteins such as EGFR in lung adenocarcinoma [115]. Studying phosphorylation (p) is tricky because serine $(\mathrm{S})$, threonine $(\mathrm{T})$, and tyrosine $(\mathrm{Y})$ have varied ratios of 1000:100:1 [116]. Among these, studying pY is very difficult due to poor abundance in the system; therefore studying $\mathrm{pY}$ in any biological setting requires enrichment of the samples to capture the maximum possible events for $\mathrm{pY}$ specific PTMs. It can be achieved using $\mathrm{pY}$ specific anti-phosphotyrosine antibodies (Clone 4G10) [115]. In contrast, pS and pT residues can be enriched easily using Titanium Dioxide $\left(\mathrm{TiO}_{2}\right)$ based enrichment method. Only one study was carried out in the multiple myeloma model of tumor reversion. The in vivo quantitative proteomics labeling technique called stable isotope labeling in animal cell culture (SILAC) was employed to identify the proteins of interest between revertant vs parental cells, and reported the significance of STAT3 in tumor reversion [21]. In SILAC, the cell line first cultured in heavy Arginine and Lysine that after subculturing for five passages leads to replacing of the unlabeled proteins by replacing light Arginine and Lysine. One of the significant differences between ITRAQ versus SILAC is that in the case of SILAC, there is a requirement of huge amount of protein. SILAC is performed on intact protein, and iTRAQ on the peptides.

Phosphorylation of RB1 inhibited at S780 residue in MCF-7 cell line after treatment with axolotl oocyte extract, and subjected to cellular reprogramming and arrest of the cell cycle as well. Furthermore, inhibition of CDK activity, and reprogramming of tumor cells occurred which leads to cell cycle arrest. The in vivo reprogrammed tumors in mouse xenograft showed a decrease in the pS780 levels of RB1 protein [101].

In breast cancer cells, the p27 expression is essential for tumor regression. Upon treatment with GGTI-2417 (a methyl ester prodrug that is a selective inhibitor of GGTase I), an accumulation of p27 protein occurs in G0/G1 phase, followed by induction of apoptosis in breast cancer cells. An accumulation of nuclear p27 in an in vivo mouse model led to regression of the tumor compared with the controls [102].

Glycosylation is another significant PTM event that has been observed in $\sim 50 \%$ of the proteins. It has been reported about tumor progression in the large number of studies. There are selected studies that are only available on the role of glycosylation in association with tumor reversion [107]. Glycosylation is mainly of three types based on glycosidic linkage: O-, C-, and N-glycosylation.

\section{Role of animal models in tumor biology}

The animal models are integral part of the cancer therapeutics-based studies. The tumor models for 


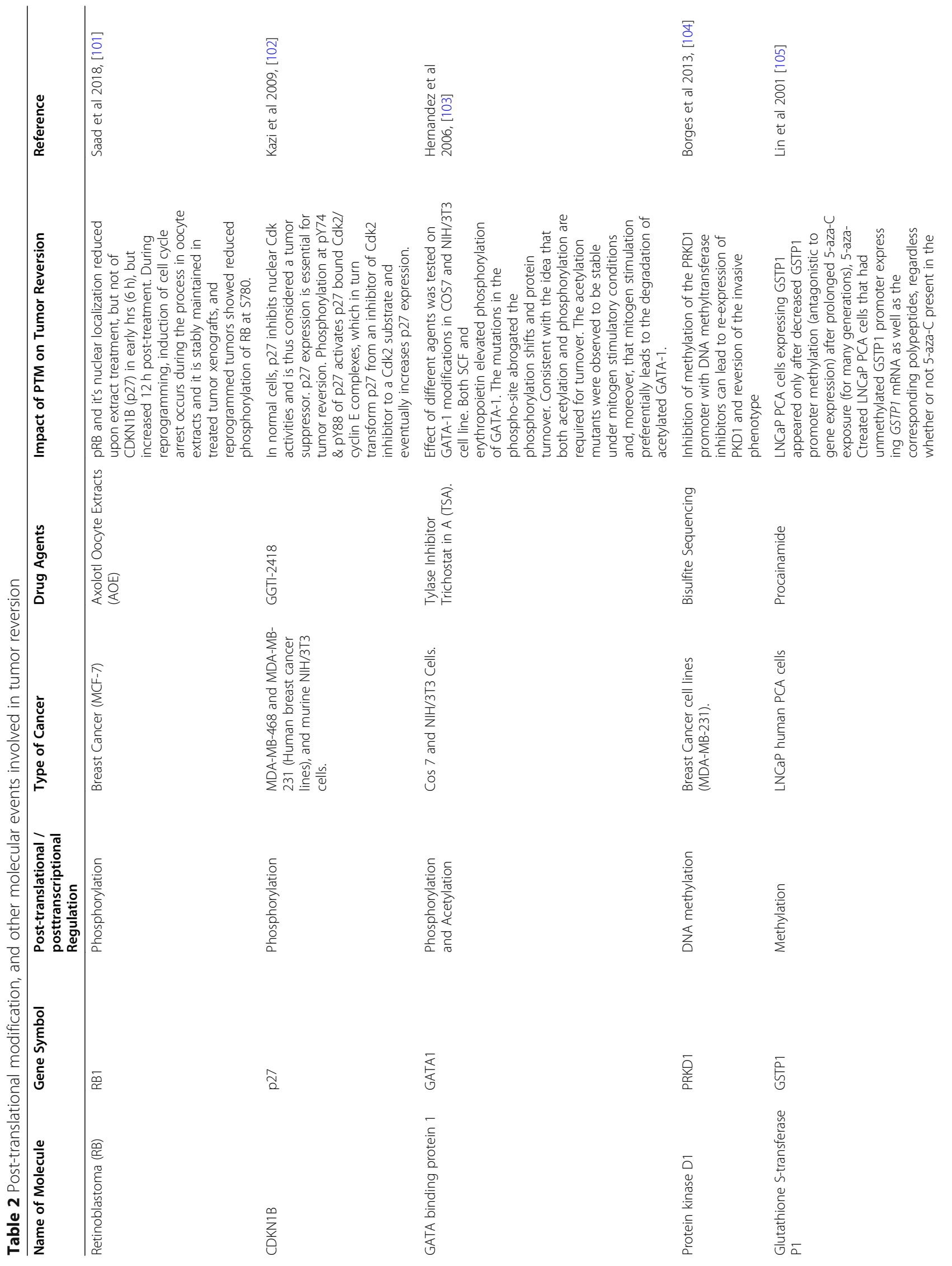




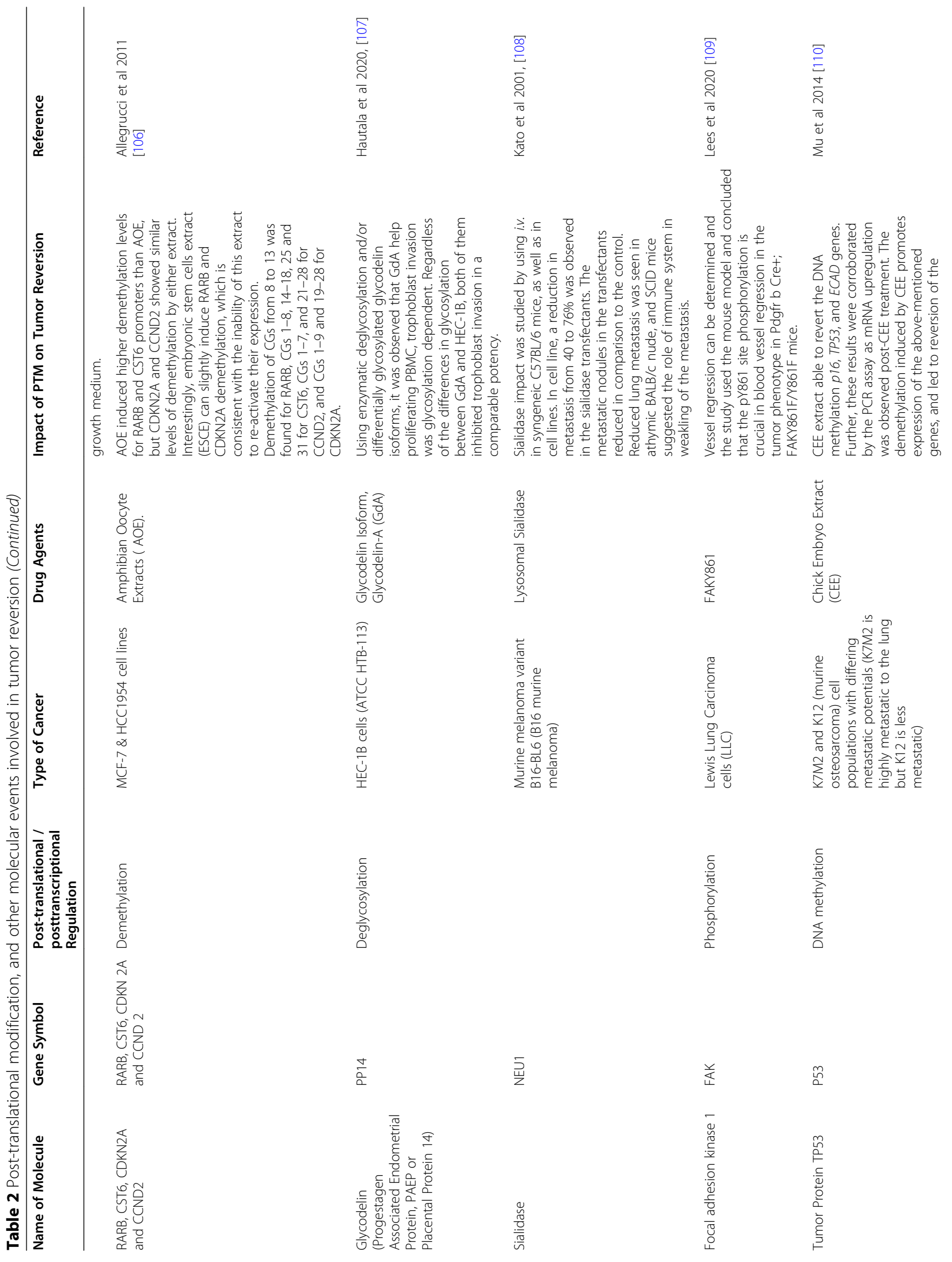




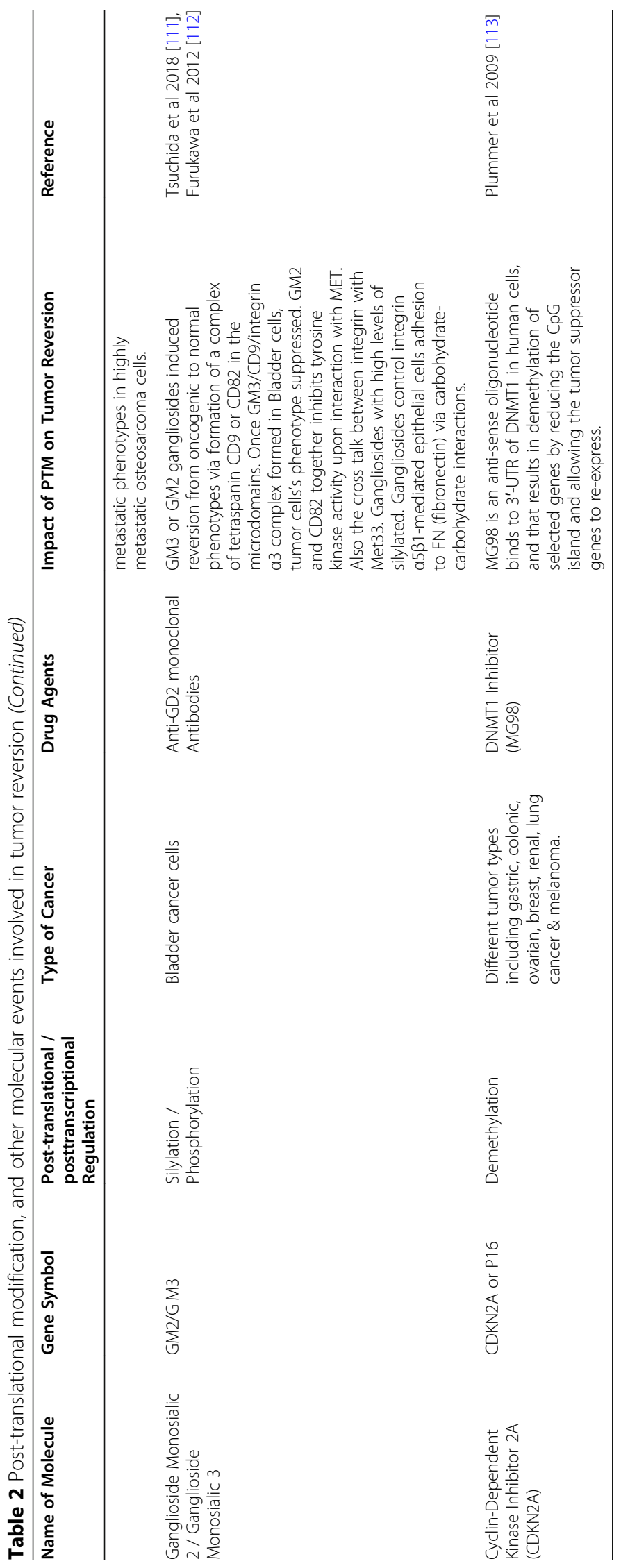


different cancers have proven to be very helpful not only in understanding the disease biology but also for the development of novel therapeutic targets. The characteristics of these mice combine the features of the NOD/ ShiLt) background, the severe combined immune deficiency mutation (SCID), and IL2 receptor gamma chain deficiency that results in lack of mature $\mathrm{T}, \mathrm{B}$, or functional NK cells, and are deficient in cytokine signaling in NSG mice leading to better engraftment of cells of interest. Some of the important animal models including SCID or transgenic used for different cancers other than tumor reversions are summarized in Table 3.

Table 3 Animal models used for different malignancies in studying tumor biology (other than tumor reversion)

\begin{tabular}{|c|c|c|c|}
\hline Model Type & Malignancy & Phenotype & References \\
\hline $\begin{array}{l}\text { CC10-rtTA; (tetO7)CMV-K } \\
\text { Ras }^{\text {G12D }} \text { (Transgenic) }\end{array}$ & Lung Cancer & $\begin{array}{l}\text { Bronchogenic adenocarcinomas. Phenotype is } \\
\text { completely reversible upon Dox removal. }\end{array}$ & Fisher et al 2001 [117] \\
\hline KPC Mouse model & Pancreatic Adenocarcinoma & $\begin{array}{l}\text { It develops important key features observed in } \\
\text { human PDA including pancreatic intraepithelial } \\
\text { neoplasia alongside a robust inflammatory } \\
\text { reaction including exclusion of effector T cells. } \\
\text { KPC mouse contains a conditional point mutation } \\
\text { in the transformation related protein } 53 \text { gene } \\
\text { TP53R172H), and a point mutation in KRAS gene } \\
\text { (KRASG12D) both of which generate non- } \\
\text { functional proteins. }\end{array}$ & Hingorani et al 2005 [118] \\
\hline
\end{tabular}

NSG mice (NOD.Cg-Prkdcscid II2rgtm 1 Wjl/Szl) used for making human esophageal tumor xenograft using TE11 cell line

NOD-SCID mice implantation with MDA-MD-231

E $\mu-T c l-1$ transgenic mouse model

human/mouse radiation chimera

$\mathrm{NOD} / \mathrm{SCID}$

Transgenic mice model with human MET in hepatocytes under the control of tetracycline

Transgenic mice model expressing KRas $4 b^{G 12 D}$ under the control of doxycycline (a form of tetracycline)

K14-rtTA/TetRE-ErbB2 Tet-On' bitransgenic mouse system
Esophageal squamous cell carcinoma

Subcutaneous treatment with pharmacological inhibitor entospletinib (GS-9973) for 10 days led to reduction in tumor growth by $55 \%$.

Breast Cancer

Chronic lymphocytic leukemia

$\mathrm{CLL}$

Hepatocellular carcinoma

hMAb173 treatment led to $60 \%$ reduction in the TNBC tumor growth compared to the control group. The microscopic study revealed that hMAb173 treatment effectively degraded AXL in tumor cells.

The TCL1 gene of human origin under the control of the immunoglobulin heavy chain variable region promoter and immunoglobulin heavy

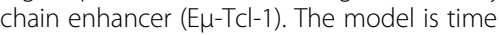
consuming due to disease delayed development, and TCL1 overexpression does not allow relextion of the genetic complexity of CLL.

Transplantation of CLL PBMC into peritoneal cavity of irradiated Balb/c or BNX mice, radioprotected with bone marrow from SCID mice.

Transplantation of CLL PBMC in NOD/SCID mice and combining intravenously and in transperitoneally injection.. However, these mice still retain normal natural killer (NK), and myeloid cells, and these cells were likely responsible for interfering with the in vivo engraftment of some human leukemia's/lymphomas.

In this study, early deaths prevented by feeding the mating parents and newborn pups doxycycline to repress expression of the MET transgene. Continued expression of MET is required for maintaining HCC.

Lung adenocarcinoma

DOX induction after two months led to development of adenoma, and adenocarcinoma of lungs, but removal of DOX in contrast caused rapid downregulation of mutant KRas RNA and auxillary apoptotic regression of an early proliferative lesions as well as tumors.

Skin carcinoma

ntil ErbB2 expression induced by doxycycline
Barbhuiya et al 2018 [119]

Wu et al 2015 [120]

Bichi et al 2002 [121]

Shimoni et al 1997 [122]

Durig et al 2007 [123].

Wang et al 2001 [124]

Fisher et al $2001[117]$ (Dox), the animals were normal, but prenatal induction led to death. Skin hyperplasia observed in animals after two days, and Dox withdrawal reverted these changes to normal. 
Role of chemical biology, and anti-therapeutic agents in tumor reversion

In addition to the availability of several cell lines and animal-based models, chemical probes have been reported to induce tumor reversion. These include not only antibodies but also natural product-based compounds such as ellipticine, thioridazine, E7107, sertraline, metformin, and thiazolidinedione (Fig. 4). Selected compounds have been discussed below, as these have been directly or indirectly impacted the process of tumor reversion.

\section{Ellipticine}

Ellipticine is a natural product of pyridoindole alkaloid naturally derived from the leaves of Ochrosia elliptica and Rauvolfia sandwicensis. Ellipticine's anti-cancer activity has been reported in a number of malignancies [126]. It can induce phenotypic reversion in tumor cells at non-cytotoxic concentrations in the cell lines [127].

\section{Thioridazine}

It is an antipsychotic drug that consists of antimicrobial activity. It can restore doxorubicin sensitivity in leukemia as well as in multidrug-resistant T-lymphoma cell lines and capable of inducing apoptosis in these cells [128]. It has been used as a tumor reverting agent because it inhibits TCTP [129].

\section{Metformin}

Metformin is prescribed as the first line of treatment for type 2 diabetes [130]. It is capable of stimulating cell survival and mitogenesis in many cancers including breast, liver, colon, pancreas, and skin [131]. It has been shown to reduce cancer by $\sim 57 \%$ in $\mathrm{T} 2 \mathrm{DM}$ patients
[132]. Metformin stimulates adenosine monophosphate (AMP)-activated protein kinase. AMPK can be directly activated by an increase in the ratio of AMP: ATP in metabolic stress including hypoxia and glucose deprivation [133]. MCF10ADCIS cell line is ductal carcinoma in situ models of breast cancer. It is capable of making irregular, large spheroids without a lumen. Still, treatment with metformin induces luminal-like morphology and also reverses overexpression of markers such as VIM, FN1, and CDH2 suggesting the role of metformin in tumor reversion.

\section{Thiazolidinedione (TZD)}

It has been used for the treatment of type 2 diabetes. TZD's phenotype treated anaplastic thyroid carcinoma cells changed to epithelial-like cell morphology. It is a typical feature observed in the differentiation of epithelial cells of thyroid origin, and also in the reversal of EMT [134].

\section{Sertraline}

It is an antidepressant drug that is an inhibitor of CYP2D6 and CYP2B6 in vitro [135]. Sertraline is used to treat non-small cell lung cancer (NSCLC); it inhibits the viability of NSCLC cells and shows synergy with erlotinib. Sertraline also has been used in the treatment of breast cancer [136]. Sertraline is used with thioridazine in cancer treatment and tumor reversion by targeting the major driver protein TCTP [129].

\section{LY294002}

LY294002, a morpholine-based compound that is a powerful inhibitor of phosphoinositide 3-kinases (PI3Ks)
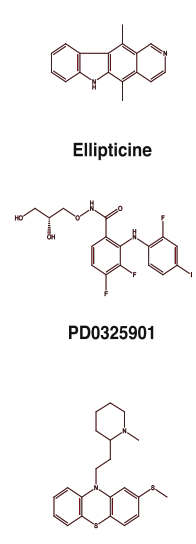

Thioridazine

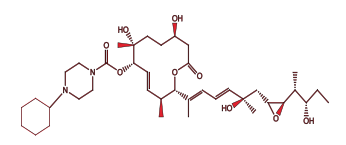

E7107
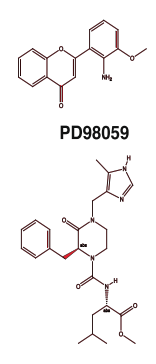
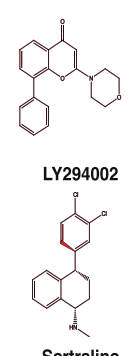

Sertraline

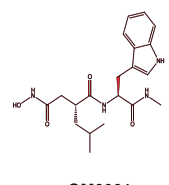

GM6001

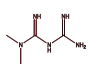

Metformin

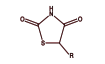

Thiazolidinedione

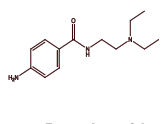

Fig. 4 The chemical structures of compounds used for induce tumor reversion. A number of compounds have been used for reverting the phenotype of a tumor into normal. The structure of the following compounds have been drawn here using ChemDraw: Ellipticine, E7107, LY294002, Metformin, PD0325901, PD98059, Sertraline, Thiazolidinedione, Thioridazine, GGTI-2417, and GM6001 
[137]. LY294002 in coordination with DAPT $(\gamma$-Secretase Inhibitor) inhibits Notch1, HES1, and pAkt in gastric cancer cells, thus inhibit metastasis of gastric cancer through mutual enhancement [138]. LY294002 and baicalein inhibit cellular proliferation and induce apoptosis in liver cells via the PI3K/Akt signaling pathway in combination with baicalein [139]. LY294002 combined with PI3K inhibitor and dibutyryl-cAMP led to tumor reversion in mammary tumor cells through cellular reprogramming of cell polarization and morphogenesis from tumorigenic to normal [140].

\section{PD0325901}

It is also called Mirdametinib, non-ATP-competitive MEK I with $\mathrm{IC}_{50}$ of $0.33 \mathrm{nM}$ in cell-free assays, roughly 500-fold more potent than CI-1040 on phosphorylation of ERK1 and ERK2. PD0325901 showed its potential in converting the tumor phenotype into the normal in an isogenic cell line model derived from MCF10A [28].

\section{E7107}

E7107 is a macrolide that is a 7-urethane derivative of pladienolide D (PLAD-D). Like pladienolide-B (PLADB), spliceostatin, Herboxidiene, and Trichostatin A; E7107 targets SF3B1 protein that is part of U2 snRNP of the spliceosome complex. The spliceosome modulator, E7107 reverses cancer aggressiveness and inhibits castration-resistant prostate carcinoma in xenograft and autochthonous prostate cancer models. Treatment of LNCap (prostate cancer cell line) with E7107 led to changes in the transcriptome, which are more like normal cells, indicates that E7107 modulates the transcriptome via modulation of spliceosome machinery by binding to the SF3B1 protein. This suggests that RNA splicing machinery also plays a vital role in the process of tumor reversion [141].

\section{In vitro, 3D-culture-based, and in vivo models for studying the tumor reversion}

The 3D models mimic more closely to in vivo behavior of cells; therefore, many studies using breast cancer as a preferred model were carried out using the 3D technique. Cancer cell culture in 3D, material, or embryonic fields fortifies the TOFT anecdotal through the microenvironment's ability to overcome the mutated genes' activity and promote the malignant phenotype's reversion. The co-culture of cancer cells with normal cells of the microenvironment can guide cells into a normal phenotype through a process of reversion via the restoration of a normal, and strong morphogenetic field [12, 142]. Additionally, 3D culture models have been used where reconstructed, but normal tissue architecture mimicking biological microenvironments was used and the tumor cells successfully novitiate the normal tissue architecture
[143]. Further, these changes make these reversed cells prone to apoptosis and differentiation, and at last culminate the reprogramming of "normal" phenotype [2, 67]. Tumor reversion has been studied in vitro, in vivo, and 3D-culture-based models. A summary of all these models is presented in Table 4.

\section{OMICS approaches for solving the puzzle of tumor reversion}

Multi-omics approaches contributed to understanding the multi-factorial diseases like cancer, diabetes, stroke, essential hypertension, and meningitis [19]. This became possible due to some of the landmark discoveries that lead to the development of techniques such as transcription activator-like effector nucleases (TALEN), zinc finger nucleases (ZFNs), and clustered regularly interspaced short palindromic repeat (CRISPR) [163].

\section{Nuclease based genome editing techniques, and shRNA screening}

Unlike CRISPR, which can introduce multiple gene mutations concurrently with a single injection, TALENs are limited to simple mutations. CRISPR transfections also have higher efficiency, whereas TALEN editing often results in mosaicism, where a mutant allele is present only in some of their transfected cells [164]. For selecting TALEN nuclease sites, $\mathrm{T}$ must be before the 5 ' - end of the target DNA sequence. The shRNA vectors generally provide high cell-to-cell uniformity within the pool of treated cells and very consistent results between experiments. In contrast, CRISPR and TALEN produce results that are highly non-uniform from cell to cell due to the stochastic nature of the mutations introduced. Not in viruses and eukaryotes, but in prokaryotes, the CRISPR/Cas system can be found naturally. The enzymatic activity of the Cas9 protein is comparable to anchor scissors. Using CRISP-Cas9, gene editing can occur anywhere in the genome, as long as the short guide RNA (sgRNA) binds upstream of a PAM sequence. The sgRNA is a fusion of crRNA and tracrRNA [165].

\section{ZFNs}

ZFNs were the first custom DNA endonucleases, which could recognize $3-4$ bps sequences and cleave the target DNA. Each zinc finger is typically made up of approximately 30 amino acid modules and is capable of recognizing 3 to 6 nucleotide bases. Since ZFN is a heterodimer (it is composed of a zinc finger domain and a Fok1 endonuclease domain), the endonuclease domain must dimerize before it can create a double-strand break in the DNA. However, this automatically happens as it recognizes the binding site. The Fok1 nucleases are also activated at this point. After cleavage, the cell then tries to repair the breakage, either through non-homologous 


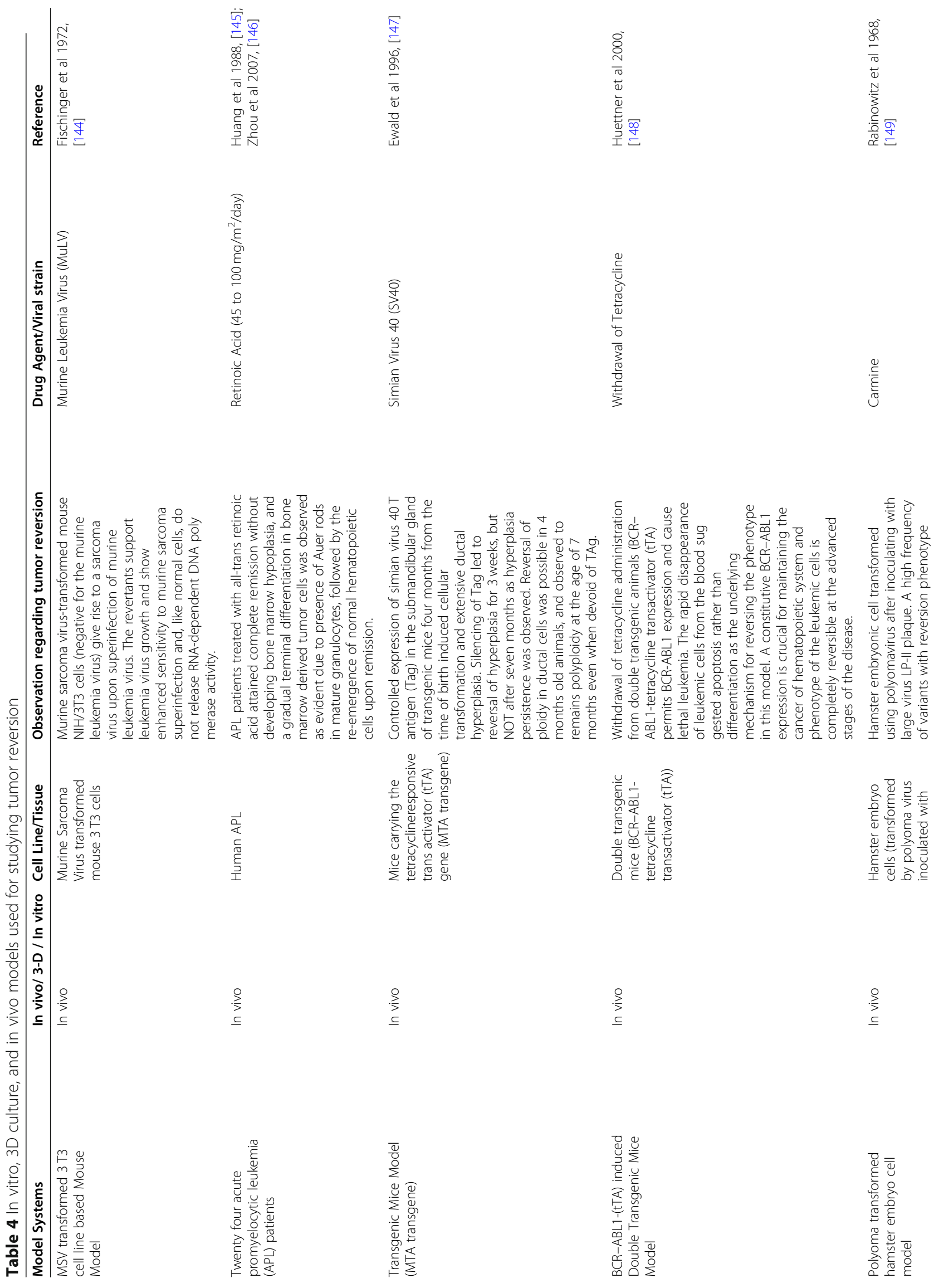




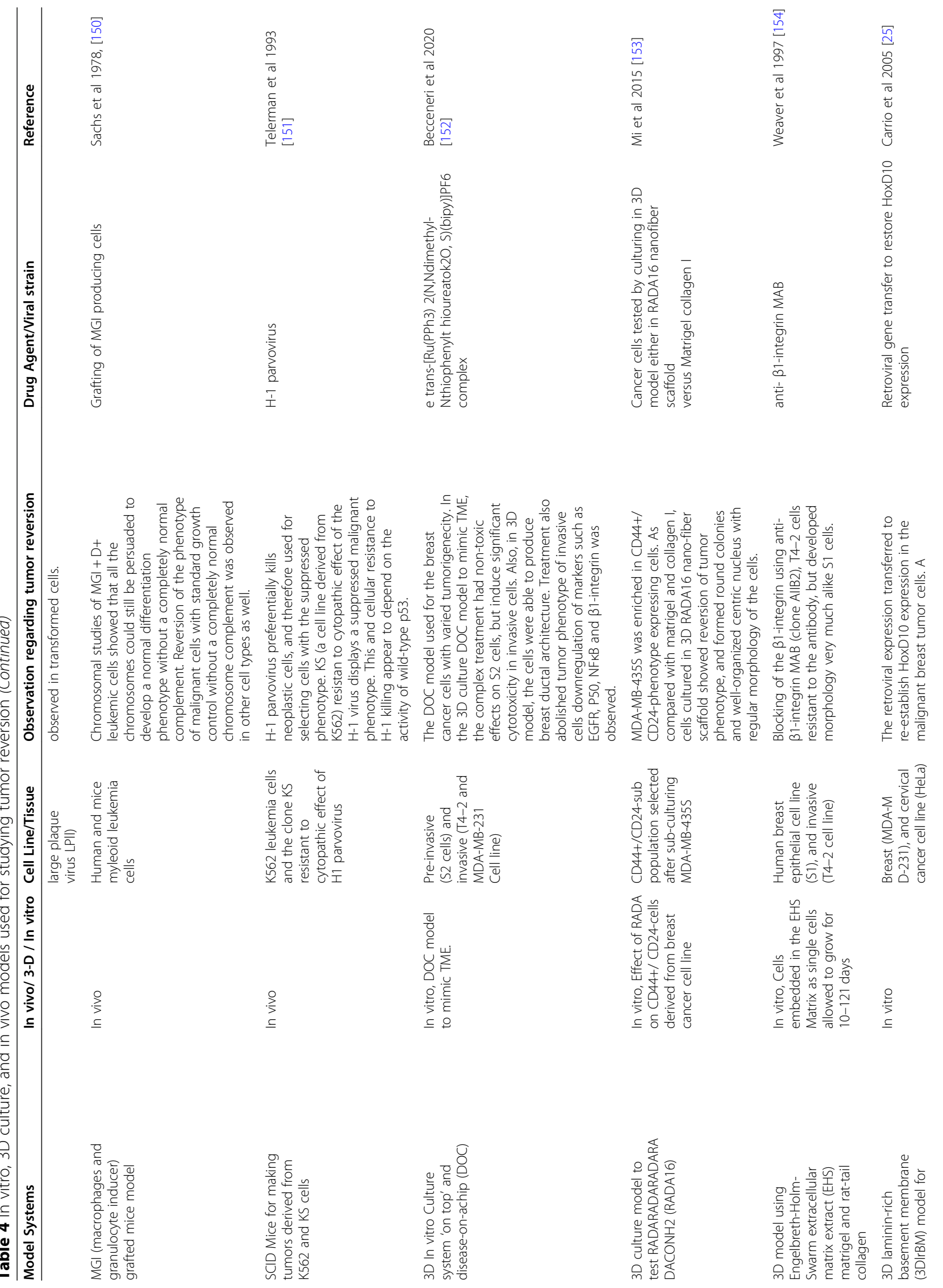




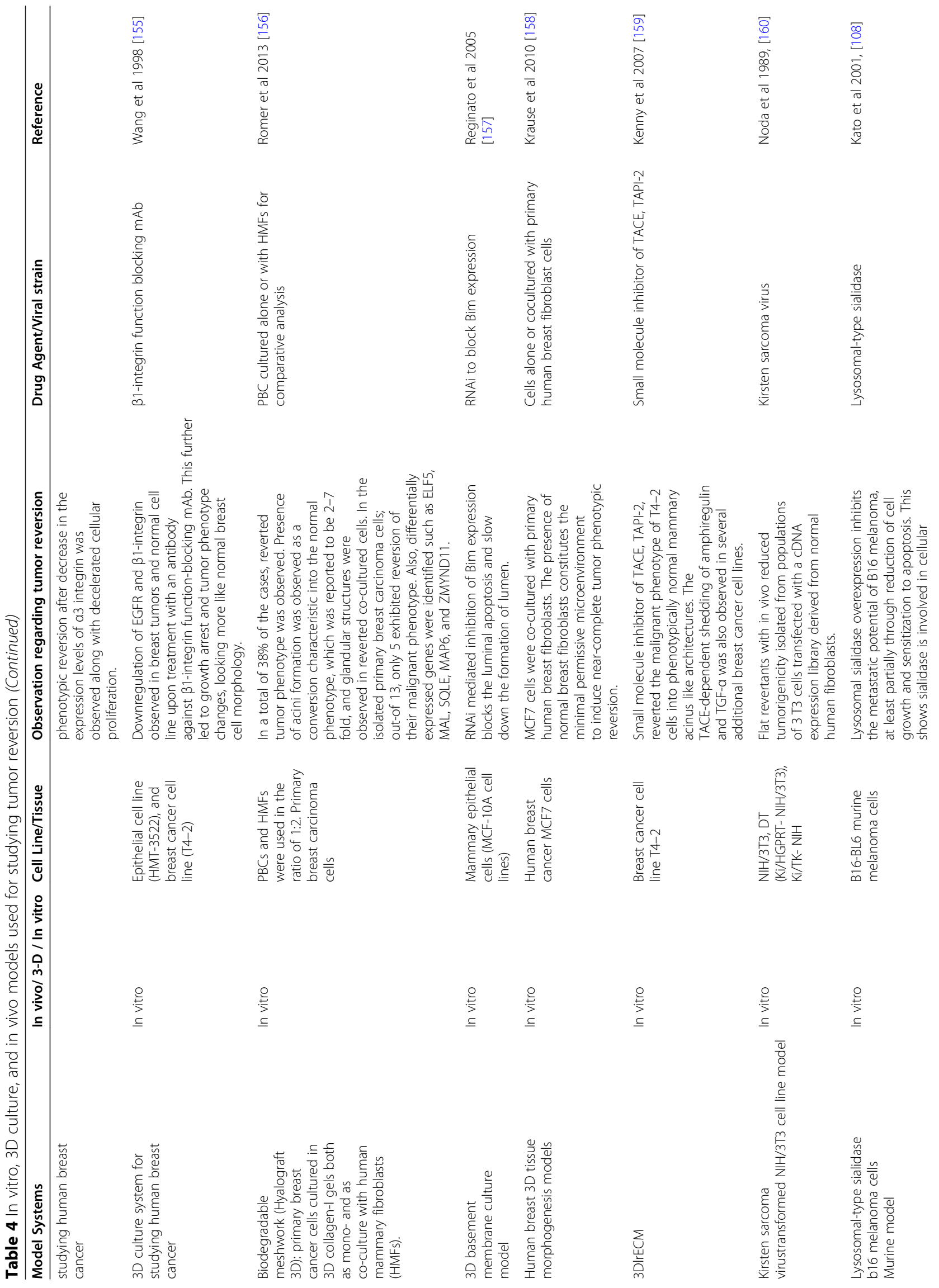




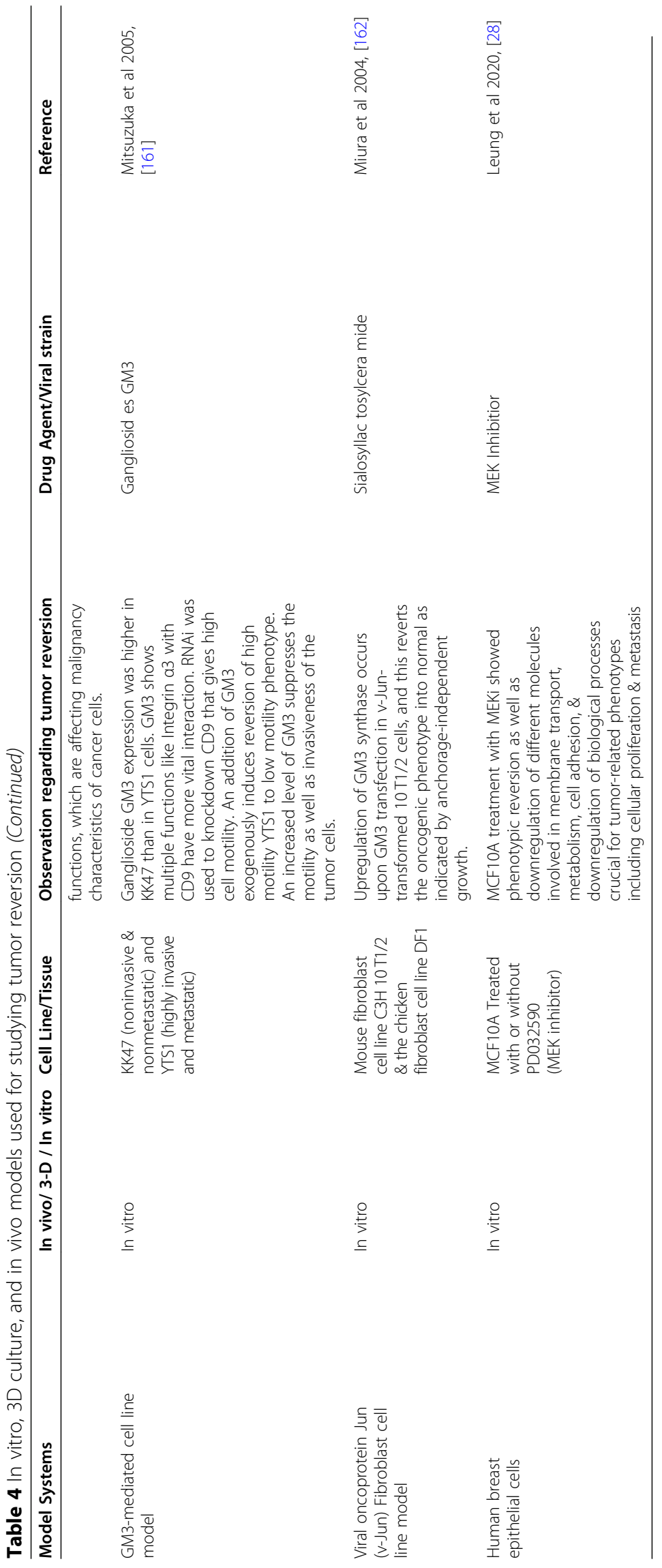


end joining (NHEJ) wherein it seals the two ends of the DNA back together, or via homology-directed repair wherein it uses a copy of the gene sequence to fix the break, thereby incorporating the desired sequence into the DNA [166]. Using ZFNs, major challenge is to predict the specificity of the final arrangement, as Zinc fingers are known to influence neighboring fingers' specificity.

\section{TALENS}

TALENs are fusion proteins (composed of a bacterial TALE protein and Fok1 endonuclease) whose specificity is derived from the protein-DNA association. It is normally comprised of 33-35 amino acid modules, each targeting a single nucleotide. Thus, by assembling different TALEN moieties, researchers can recognize any specific DNA sequence they like. Compared to ZFNs, TALENs are cheaper and produce faster results. They are also more flexible and easier to design due to their welldefined target specificities (the activity of each TALE does not affect the binding specificity of neighboring TALEs). However, both techniques are not limited to mutagenesis in mouse embryonic stem cells and have been successfully used to engineer modifications in several animal and insect species (e.g. zebrafish, rats, livestock, fruit flies, monarch butterflies, and nematodes). The note of caution is that TALEN motifs are also linked with Fok1 endonuclease, so dimerization is required before it can successfully cleave the DNA [167].

\section{Clustered regularly interspaced short palindromic repeat/ CRISPR associated 9 (CRISPR/Cas9)}

CRISPR/Cas9 is an RNA-based bacterial defense mechanism composed of two types of RNA (one being the trans-activating crRNA and a single guide RNA) and Cas9 endonuclease. While the other two systems are both man-made, the CRISPR/Cas system is derived from bacteria. In nature, the CRISPR system is activated when a virus or foreign pathogen invades a bacterium. With the help of the appropriate Cas proteins, the system captures and cuts a portion of the viral DNA and incorporates it into the CRISPR locus of the bacterial genome [168]. When the same virus attacks the bacterium, the CRISPR loci produce guide RNA (gRNA), which takes the Cas proteins to the matching target sequence in the viral DNA. The Cas proteins then bind to the target and cleave the viral DNA at a specific location, rendering it inactive. Compared to ZFNs and TALENs, the CRISPR/ Cas9 system is undeniably simpler, cheaper, and more efficient [165]. Notably, the CRISPR/Cas9 system can be designed for any genomic targets and multiplexed by adding multiple gRNAs.

Genome editing advanced techniques such as CRISPR could be exploited in addition to the classical human $\mathrm{H} 1$ parvovirus mediated generation of revertants. CRISPR was successfully used for genome editing of the MDAMB-231 cell line to convert its aggressive phenotype into a mild one [29]. CRISPR could be used for generating models for cancers that have not been studied so far by focusing on tumor reversion. CRISPR allows creating a mutant or knockout of a particular gene without much hassle.

\section{Target discovery using shRNA screening}

The major difference between shRNAs and siRNA is that shRNAs can stably integrate into the genome through virus-mediated transduction, but siRNAs transiently expressed in the cells. siRNA sequences between 19 and 29 nt are generally the most effective. Between siRNAs and miRs, siRNAs originate predominantly from exogenous dsRNA, but in contrast, miRNAs originate from the genome of the cell. siRNA-mediated gene silencing represents a cell defense mechanism against exogenous dsRNA, and miRNA-mediated gene silencing is an integral gene expression regulation process. In the case of siRNA, it is generated when the double-stranded RNA cleaved by a nuclease called Dicer. Inactivation of RNA using siRNAs referred to as RNA interference. TCTP has been studied using shRNA in breast cancer where inhibition of TCTP by shRNA led to induction in the expression of TP53 with a significant decrease in sphere-forming efficiency [169]. Another good example where lipogenesis was suppressed using shRNA by targeting FASN in breast cancer which led to tumor reversion [30]. Screening the shRNA library could help us in identifying the targets for tumor reversion as it was done in some other conditions such as reversion of multidrug resistance in some cancers.

The gene expression plays a vital role in transforming the phenotype of the malignant cells into normal cells. Techniques like RNAseq could be crucial in delineating the alternative RNA splicing events to identify differentially regulated AS events such as intron retention, exon skipping, alternative 3'SS, and 5'SS between normal vs. cancer cell types. Furthermore, RNAseq can help to identify crucial lncRNAs playing a significant role in tumor reversion, as we were unable to find even a single studyreporting role of lncRNAs involved in tumor reversion.

Among multi-omics techniques, proteomics-based techniques are crucial as they provide the landscape of overall proteome and shed light on changes in the PTMs $[101,102,115]$.

Suppose we want to study and understand tumor reversion in a better way. In that case, we must explore different cancer-specific models using the high-throughput multi-omics study to make a compendium of differential proteins regulated involved in control as well as in the regulation of the process of tumor reversion. 
The cell line models with various tumorigenicity levels could be ideal for dissecting the mechanism of tumor reversion. Among those, the MCF10A cell line with other variants like pre-neoplastic (MCF10A-T1K or T1K), MCF10CA1h or CA1h (low-grade), and MCF10CA1a or CA1a (high-grade) could be used for exploration of tumor reversion by implementing in vitro proteomics techniques, [170] such as isobaric tagging for absolute quantitation (iTRAQ) coupled with LC-MS/MS. Interestingly, this is the only study so far carried out in any of the malignancies to study tumor reversion. These kinds of models have the advantage of prohibiting genetic variants' entry because all these are in the same genetic background. Furthermore, the 8-plex iTRAQ quantitative proteomics labeling technique allows running the technical replicates in parallel i.e., a maximum of eight samples can be compared and analyzed [171]. The iTRAQ technique has advantages in terms of the usage of less amount of protein $(50 \mu \mathrm{g}) \mathrm{com}$ pared with other methods. It enables quantitation of proteins and peptides by labeling the samples with isotope encoded reporter ions.

\section{Small molecule library screening in tumor reversion}

Small molecule library screening in a high-throughput manner could help in the discovery of chemical leads that are the potential starting point in the tumor reversion process. HTS led to the identification of a novel p110- $\delta$ inhibitor that accelerates the anti-myeloma effect of bortezomib [172]. This facilitates rapid evaluation of thousands of small molecules in physiologically and biologically relevant assays for tumor reversion. The H1 parvovirus-based cell line models of tumor reversion could be ideal for HTS to identify the lead small molecule with the potential to induce tumor reversion.

\section{Challenges and future perspectives}

Amongst reverting the phenotype approaches, reversion of M2-like TAMs to the tumor-suppressive phenotype by modulating the TME is the most promising one because phenotypes of macrophages are highly sensitive to TME stimuli [173].

In vitro and in vivo labeling techniques coupled with LC-MS/MS must be applied to find differentially regulated proteins crucial for cellular reprogramming and tumor phenotype reversion. Additionally, these highthroughput techniques could help in identifying the PTMs crucial for this biological process. Also, studies have shown that proteins with basic nature such as histones are prone to PTMs, and various studies have shown that miRs can target and regulate histones at specific positions [174].

A number of studies directly or indirectly supporting the fact that it is possible to change (complete or partially) the morphological behavior of the tumor cells exactly or nearly like a normal cell. Some of the difficult questions still need to be addressed if tumor reversion can be recapitulated among all types of malignancies. Will it be an alternative to treatment options like chemotherapy in the near future? The tumor regression model ideally in the same genetic background could be the best starting point using quantitative proteomics approaches such as SILAC and transcriptomics approach using RNAseq to address the significantly altered changes at protein and RNA levels. It is important from a therapeutic perspective that it works at the molecular level and drives a cancer cell to lose its malignancy by halting the tumor progression. So activating the tumor reversion pathway or mimicking, could be a promising potential treatment option for cancer.

\section{Conclusion}

The molecular biology behind the process of tumor reversion is not only interesting but intriguing as well. The experimental evidence from different studies clearly suggests the usefulness of handful of molecules, including miR, post-transcriptional events in certain genes, and proteins with associated PTMs as potential agents for phenotypic tumor reversion. To date, making tumor reversion, as a treatment option remains a dream, but evidences, all together suggest more molecular layers derived from indepth analysis using multi-omics approaches and shreds of evidence, all together suggests that this dream could become a reality in the near future.

\section{Abbreviations}

ASO: Anti-sense oligonucleotide; CAFs: Cancer-associated fibroblasts; CLL: Chronic lymphocytic leukemia; CRISPR: Clustered Regularly Interspaced Short Palindromic Repeat; EMT: Epithelial-mesenchymal transition; ES: Exon skipping; GC: Gastric cancer; HCC: Hepatocellular carcinoma; HTS: Highthroughput screening; IHC: Immunohistochemistry; IR: Intron retention; iTRAQ: Isobaric tagging for absolute quantitation; KO: Knockout; LC/MS/ MS: Liquid Chromatography Tandem-Mass Spectrometry; LN: Lymph node; LOH: Loss of heterozygosity; MET: Mesenchymal epithelial transition; miRNA: microRNA or miR; ncRNA: non-coding RNA; NFs: Normal fibroblasts; PKM: Pyruvate Kinase muscle isoenzyme; PPI: Protein-protein interaction; PTM: Post-translational modifications; PSEN1: Presenilin 1; RAP1-A: Ras-related protein Rap-1A; RNAi: RNA interference; RPKM: Reads per kilo base per million mapped reads; SCID: Severe combined immunodeficiency; SIAH1: Siah E3 ubiquitin protein ligase 1; SILAC: Stable isotope labeling in animal cell culture; SMT: Somatic mutation theory; SPLMs: Splicing modulators; SOC: Standard of care; SRSF1: Serine and arginine rich splicing factor 1; SS: Splice site; STAT3: Signal transducer and activator of transcription 3: TAM: Tumor associated macrophages; TALEN: Transcription activator-like effector nucleases; TCTP1: Translationally controlled tumor protein 1; TFs: Transcription factors; TME: Tumor microenvironment; TOFT: Tissue organization field theory; TSAP6: Tumor suppressor activated pathway 6; TSG: Tumor suppressor gene; UTR: Untranslated region; Y2H: Yeast twohybrid; ZFN: Zinc finger nuclease

\section{Supplementary Information}

The online version contains supplementary material available at https://doi. org/10.1186/s40364-021-00280-1.

Additional file 1. 


\section{Acknowledgements}

The funders had no role in study design, data collection, and analysis, decision to publish, or preparation of the manuscript.

\section{Authors' contributions}

AT, AK, and GT contributed equally to this study. MKK designed and guided the research study. MKK, AT, AK, and GT carried out an exhaustive search and analyzed the data. MKK, AT, GT, and AK wrote the manuscript. ACB, AH, YV, $H Z$, JY, RB, NA, AKS, KT, MJ, and AC critically edited, evaluated and, gave their feedback on the manuscript. All the authors have read, critically evaluated, and approved it for submission.

\section{Funding}

MKK is the recipient of the TARE fellowship (Grant \# TAR/2018/001054) from the Science and Engineering Research Board (SERB), Department of Science and Technology, Government of India. The study was partly supported by research grants to ACB (sanction no.- 5/13/38/2014-NCD-III) from ICMR, and (EMR/2017/004018) from DST-SERB; SRFship to KT (5/13/38/2014 NCDIIIEoffice73143) from ICMR, senior research fellowship to NA (09/045(1622)/ 2019-EMR-I), junior research fellowship to JY (09/045(1629)/2019-EMR-I) and RB (09/045(1672)/2019-EMR-I) from CSIR, and JRFship to AC [573(CSIR-UGC NET JUNE 2017)] from UGC.

\section{Availability of data and materials}

All data generated and analyzed during our study are included either in the published article or supplementary data associated with the manuscript.

\section{Declarations}

\section{Ethics approval and consent to participate}

Not applicable because the data included in the study was collected from published studies on tumor reversion. The study does not involve any human subjects, tissue samples or cell lines.

\section{Consent for publication}

All authors consent to the publication of the manuscript in Biomarker Research. Further, figures or tables are original, so there was no requirement of taking permission or consent from anyone.

\section{Competing interests}

The authors declare no conflict of interest.

\section{Author details}

'Amity Stem Cell Institute, Amity Medical School, Amity University Haryana, Panchgaon, Haryana, Manesar (Gurugram) -122413, India. ${ }^{2}$ Department of Biotechnology, Thapar Institute of Engineering \& Technology, Patiala, Punjab, India. ${ }^{3}$ Department of Zoology, Molecular Oncology Laboratory, University of Delhi (North Campus), New Delhi 110007, India. ${ }^{4}$ Department of Medical Laboratory Technology, Amity Medical School, Amity University Haryana, Panchgaon, Haryana, Manesar (Gurugram), India. ${ }^{5}$ Department of Pathology and Laboratory Medicine, Medanta-The Medicity, Haryana, Gurugram, India. ${ }^{6}$ Department of Toxicology, C C S University, Meerut, UP 250004, India. ${ }^{7}$ Department of Biomedical Sciences, College of Health Sciences, QU Health, Qatar University, Doha, Qatar. ${ }^{8}$ Centre for Science \& Society, Indian Institute of Science Education and Research (IISER), Bhopal, India. Innovation and Incubation Centre for Entrepreneurship (IICE), Indian Institute of Science Education and Research (IISER), Bhopal, India.

\section{Received: 25 January 2021 Accepted: 30 March 2021}

\section{Published online: 06 May 2021}

\section{References}

1. Bray F, Ferlay J, Soerjomataram I, Siegel RL, Torre LA, Jemal A. Global cancer statistics 2018: GLOBOCAN estimates of incidence and mortality worldwide for 36 cancers in 185 countries. CA Cancer J Clin. 2018;(68):394-424.

2. Kenny PA, Bissell MJ. Tumor reversion: correction of malignant behavior by microenvironmental cues. Int J Cancer. 2003;107:688-95.

3. Soto AM, Sonnenschein C. The somatic mutation theory of cancer: growing problems with the paradigm? Bioessays. 2004;26(10):1097-107.

4. Weinberg RA. One renegade cell : how cancer begins. New York: Publisher: New York : Basic Books; 1999.
5. Alberts B, Johnson A, Lewis J, Raff M, Roberts K, Walter P. Molecular Biology of the Cell. New York: Garland Publishing Inc; 2002. p. 1015.

6. Hanahan D, Weinberg RA. The hallmarks of cancer. Cell. 2000;100:57-70.

7. Soto $A M$, Sonnenschein $C$. The tissue organization field theory of cancer: a testable replacement for the somatic mutation theory. Bioessays. 2011;33:332-40.

8. Sonnenschein C, Soto AM. Somatic mutation theory of carcinogenesis: why it should be dropped and replaced. Mol Carcinog. 2000;29:205-11.

9. Jung $H$, Lee $D$, Lee J, Park D, Kim YJ, Park WY, et al. Intron retention is a widespread mechanism of tumor-suppressor inactivation. Nat Genet. 2015; 47:1242-8.

10. Amson $\mathrm{R}$, Karp JE, Telerman A. Lessons from tumor reversion for cancer treatment. Curr Opin Oncol. 2013;25:59-65.

11. Askanazy M. Die Teratome nach ihrem Bau, ihrem Verlauf, ihrer Genese und im Vergleich zum experimentellen Teratoid. Verhandl Deutsch Pathol. 1907; 11:39-82.

12. Bizzarri M, Cucina A, Biava PM, Proietti S, D'Anselmi F, Dinicola S, et al. Embryonic morphogenetic field induces phenotypic reversion in cancer cells. Review article. Curr Pharm Biotechnol. 2011;12(2):243-53.

13. Telerman A, Amson R. The molecular programme of tumour reversion: the steps beyond malignant transformation. Nat Rev Cancer. 2009;9:206-16.

14. Bommer U, Telerman A. Dysregulation of TCTP in biological processes and diseases. Cells. 2020;9:1632.

15. Tuynder M, Susini L, Prieur S, Besse S, Fiucci G, Amson R, et al. Biological models and genes of tumor reversion: cellular reprogramming through tpt1/TCTP and SIAH-1. Proc Natl Acad Sci U S A. 2002;99:14976-81.

16. Benoit RM, Eiseman J, Jacobs SC, Kyprianou N. Reversion of human prostate tumorigenic growth by azatyrosine. Urology. 1995;46:370-7.

17. Lin KK, Harrell MI, Oza AM, Oaknin A, Ray-Coquard I, Tinker AV, et al. BRCA reversion mutations in circulating tumor DNA predict primary and acquired resistance to the PARP inhibitor Rucaparib in high-grade ovarian carcinoma. Cancer Discov. 2019:9:210-9.

18. Li Y, Agrawal I, Gong Z. Reversion of tumor hepatocytes to normal hepatocytes during liver tumor regression in an oncogene-expressing transgenic zebrafish model. Dis Model Mech. 2019;12(10):dmm039578.

19. Sharma J, Balakrishnan L, Kaushik S, Kashyap MK. Editorial: multi-Omics approaches to study signaling pathways. Front Bioeng Biotechnol. 2020;8: 829. https://doi.org/10.3389/fbioe.2020.00829.

20. Roperch JP, Alvaro V, Prieur S, Tuynder M, Nemani M, Lethrosne F, et al. Inhibition of presenilin 1 expression is promoted by p53 and p21WAF-1 and results in apoptosis and tumor suppression. Nat Med. 1998;4:835-8.

21. Ge F, Zhang L, Tao SC, Kitazato K, Zhang ZP, Zhang XE, et al. Quantitative proteomic analysis of tumor reversion in multiple myeloma cells. J Proteome Res. 2011;10:845-55.

22. Yuan J, Zhang F, You M, Yang Q. Identification of protein kinase inhibitors to reprogram breast cancer cells. Cell Death Dis. 2018;9(9):915.

23. Lee S, Lee C, Hwang CY, Kim D, Han Y, Hong SN, et al. Network inference analysis identifies SETDB1 as a key regulator for reverting colorectal Cancer cells into differentiated Normal-like cells. Mol Cancer Res. 2020;18:118-29.

24. Wang F, Hansen RK, Radisky D, Yoneda T, Barcellos-Hoff MH, Petersen OW, et al. Phenotypic reversion or death of cancer cells by altering signaling pathways in three-dimensional contexts. J Natl Cancer Inst. 2002;94:1494-503.

25. Carrio M, Arderiu G, Myers C, Boudreau NJ. Homeobox D10 induces phenotypic reversion of breast tumor cells in a three-dimensional culture model. Cancer Res. 2005;65:7177-85.

26. Beliveau A, Mott JD, Lo A, Chen El, Koller AA, Yaswen P, et al. Raf-induced MMP9 disrupts tissue architecture of human breast cells in threedimensional culture and is necessary for tumor growth in vivo. Genes Dev. 2010:24:2800-11.

27. Coussens LM, Fingleton B, Matrisian LM. Matrix metalloproteinase inhibitors and cancer: trials and tribulations. Science. 2002;295(5564):2387-92.

28. Leung KK, Wilson GM, Kirkemo LL, Riley NM, Coon JJ, Wells JA. Broad and thematic remodeling of the surfaceome and glycoproteome on isogenic cells transformed with driving proliferative oncogenes. Proc Natl Acad Sci U S A. 2020;117:7764-75.

29. Yang $F$, Cui $P, L u Y$, Zhang $X$. Requirement of the transcription factor YB-1 for maintaining the stemness of cancer stem cells and reverting differentiated cancer cells into cancer stem cells. Stem Cell Res Ther. 2019; 10:233. 
30. Gonzalez-Guerrico AM, Espinoza I, Schroeder B, Park CH, Kvp CM, Khurana A, et al. Suppression of endogenous lipogenesis induces reversion of the malignant phenotype and normalized differentiation in breast cancer. Oncotarget. 2016;7:71151-68.

31. Bosch A, Bertran SP, Lu Y, Garcia A, Jones AM, Dawson Ml, et al. Reversal by RARa agonist Am580 of c-Myc-induced imbalance in RARa/RARy expression during MMTV-Myc tumorigenesis. Breast Cancer Res. 2012;14:R121.

32. Keshava Prasad TS, Goel R, Kandasamy K, Keerthikumar S, Kumar S, Mathivanan S, et al. Human protein reference database--2009 update. Nucleic Acids Res. 2009;37:D767-72.

33. Li S, Chen M, Xiong Q, Zhang J, Cui Z, Ge F. Characterization of the Translationally controlled tumor protein (TCTP) Interactome reveals novel binding Partners in Human Cancer Cells. J Proteome Res. 2016;15:3741-51.

34. Fields S, Song O. A novel genetic system to detect protein-protein interactions. Nature. 1989;340:245-6.

35. Walhout AJ, Boulton SJ, Vidal M. Yeast two-hybrid systems and protein interaction mapping projects for yeast and worm. Yeast. 2000;17:88-94.

36. Vidal M, Fields S. The yeast two-hybrid assay: still finding connections after 25 years. Nat Methods. 2014;11:1203-6.

37. Chen C, Deng Y, Hua M, Xi Q, Liu R, Yang S, et al. Expression and clinica role of TCTP in epithelial ovarian cancer. J Mol Histol. 2015:46:145-56.

38. Kim CJ, Cho YG, Park CH, Jeong SW, Nam SW, Kim SY, et al. Inactivating mutations of the Siah-1 gene in gastric cancer. Oncogene. 2004;23:8591-6.

39. Ji L, Jiang B, Jiang $X$, Charlat $O$, Chen A, Mickanin $C$, et al. The SIAH E3 ubiquitin ligases promote Wnt/B-catenin signaling through mediating Wntinduced Axin degradation. Genes Dev. 2017;31:904-15.

40. Matsuo K, Satoh S, Okabe H, Nomura A, Maeda T, Yamaoka Y, et al. SIAH1 inactivation correlates with tumor progression in hepatocellular carcinomas. Genes Chromosomes Cancer. 2003;36:283-91.

41. Xiao Z, Wei Z, Deng D, Zheng Z, Zhao Y, Jiang S, et al. Downregulation of Siah1 promotes colorectal cancer cell proliferation and migration by regulating AKT and YAP ubiquitylation and proteasome degradation. Cancer Cell Int. 2020;20:50.

42. Li $P$, Lin $X$, Zhang JR, Li Y, Lu J, Huang FC, et al. The expression of presenilin 1 enhances carcinogenesis and metastasis in gastric cancer. Oncotarget. 2016;7:10650-62.

43. Passer BJ, Nancy-Portebois V, Amzallag N, Prieur S, Cans C, Roborel de Climens A, et al. The p53-inducible TSAP6 gene product regulates apoptosis and the cell cycle and interacts with nix and the Myt1 kinase. Proc Natl Acad Sci U S A. 2003;100:2284-9.

44. Lespagnol A, Duflaut D, Beekman C, Blanc L, Fiucci G, Marine JC, et al. Exosome secretion, including the DNA damage-induced p53-dependent secretory pathway, is severely compromised in TSAP6/Steap3-null mice. Cell Death Differ. 2008;15(11):1723-33. https://doi.org/10.1038/cdd.2008.104.

45. Li Q, Xu A, Chu Y, Chen T, Li H, Yao L, et al. Rap1A promotes esophagea squamous cell carcinoma metastasis through the AKT signaling pathway. Oncol Rep. 2019;42:1815-24.

46. Liu L, Yan $X$, Wu D, Yang Y, Li M, Su Y, et al. High expression of Rasrelated protein $1 \mathrm{~A}$ promotes an aggressive phenotype in colorectal cancer via PTEN/FOXO3/CCND1 pathway. J Exp Clin Cancer Res. 2018; 37:178.

47. Dellas A, Schultheiss E, Leivas MR, Moch H, Torhorst J. Association of p27Kip1, cyclin E and c-myc expression with progression and prognosis in HPV-positive cervical neoplasms. Anticancer Res. 1998;18:3991-8.

48. Carroll PA, Freie BW, Mathsyaraja H, Eisenman RN. The MYC transcription factor network: balancing metabolism, proliferation and oncogenesis. Front Med. 2018;12:412-25.

49. Duffy MJ, O'Grady S, Tang M, Crown J. MYC as a target for cancer treatment. Cancer Treat Rev. 2021;94:102154.

50. Shou Y, Martelli ML, Gabrea A, Qi Y, Brents LA, Roschke A, et al. Diverse karyotypic abnormalities of the c-myc locus associated with c-myc dysregulation and tumor progression in multiple myeloma. Proc Natl Acad Sci U S A. 2000;97:228-33.

51. Li S, Zhang S, Chen J. c-Myc induced upregulation of long non-coding RNA SNHG16 enhances progression and carcinogenesis in oral squamous cell carcinoma. Cancer Gene Ther. 2019:26:400-10.

52. Jain M, Arvanitis C, Chu K, Dewey W, Leonhardt E, Trinh M, et al. Sustained loss of a neoplastic phenotype by brief inactivation of MYC. Science. 2002; 297:102-4.

53. Felsher DW, Bishop JM. Reversible tumorigenesis by MYC in hematopoietic lineages. Mol Cell. 1999;4:199-207.
54. Shachaf CM, Kopelman AM, Arvanitis C, Karlsson A, Beer S, Mandl S, et al. MYC inactivation uncovers pluripotent differentiation and tumour dormancy in hepatocellular cancer. Nature. 2004;431:1112-7.

55. Boxer RB, Jang JW, Sintasath L, Chodosh LA. Lack of sustained regression of C-MYC-induced mammary adenocarcinomas following brief or prolonged MYC inactivation. Cancer Cell. 2004;6:577-86.

56. Li Y, Casey SC, Felsher DW. Inactivation of MYC reverses tumorigenesis. J Intern Med. 2014;276:52-60.

57. Shachaf CM, Felsher DW. Tumor dormancy and MYC inactivation: pushing cancer to the brink of normalcy. Cancer Res. 2005;65:4471-4.

58. Marinkovic D, Marinkovic T, Mahr B, Hess J, Wirth T. Reversible lymphomagenesis in conditionally c-MYC expressing mice. Int J Cancer. 2004;110:336-42. https://doi.org/10.1002/ijc.20099.

59. Pelengaris S, Khan M, Evan Gl. Suppression of Myc-induced apoptosis in beta cells exposes multiple oncogenic properties of Myc and triggers carcinogenic progression. Cell. 2002;109:321-34.

60. Ansell SM, Vonderheide RH. Cellular composition of the tumor microenvironment. Am Soc Clin Oncol Educ. 2013;33:e91-e97.

61. Balkwill FR, Capasso M, Hagemann T. The tumor microenvironment at a glance. J Cell Sci. 2012;125:5591-6.

62. Anari F, Ramamurthy C, Zibelman M. Impact of tumor microenvironment composition on therapeutic responses and clinical outcomes in cancer. Future Oncol. 2018:14:1409-21.

63. Ingber DE. Can cancer be reversed by engineering the tumor microenvironment? Semin Cancer Biol. 2008;18:356-64.

64. Cassetta L, Pollard JW. Targeting macrophages: therapeutic approaches in cancer. Nat Rev Drug Discov. 2018;17:887-904.

65. Hagemann T, Lawrence T, McNeish I, Charles KA, Kulbe H, Thompson RG, et al. "Re-educating" tumor-associated macrophages by targeting NFkappaB. J Exp Med. 2008;205(6):1261-8.

66. Pyonteck SM, Akkari L, Schuhmacher AJ, Bowman RL, Sevenich L, Quail DF, et al. CSF-1R inhibition alters macrophage polarization and blocks glioma progression. Nat Med. 2013;19:1264-72.

67. Hendrix MJ, Seftor EA, Seftor RE, Kasemeier-Kulesa J, Kulesa PM, Postovit LM Reprogramming metastatic tumour cells with embryonic microenvironments. Nat Rev Cancer. 2007:7:246-55.

68. Postovit LM, Margaryan NV, Seftor EA, Kirschmann DA, Lipavsky A, Wheaton WW, et al. Human embryonic stem cell microenvironment suppresses the tumorigenic phenotype of aggressive cancer cells. Proc Natl Acad Sci U S A. 2008;105:4329-34.

69. Bissell MJ, Kenny PA, Radisky DC. Microenvironmental regulators of tissue structure and function also regulate tumor induction and progression: the role of extracellular matrix and its degrading enzymes. Cold Spring Harb Symp Quant Biol. 2005;70:343-56.

70. Venables JP. Aberrant and alternative splicing in cancer. Cancer Res. 2004; 64:7647-54

71. Ghigna C, De Toledo M, Bonomi S, Valacca C, Gallo S, Apicella M, et al. Pro-metastatic splicing of Ron proto-oncogene mRNA can be reversed: therapeutic potential of bifunctional oligonucleotides and indole derivatives. RNA Biol. 2010;7:495-503. https://doi.org/10.4161/rna.7.4.12 744.

72. Yadav S, Bhagat SD, Gupta A, Samaiya A, Srivastava A, Shukla S. Dietaryphytochemical mediated reversion of cancer-specific splicing inhibits Warburg effect in head and neck cancer. BMC Cancer. 2019;19:1031.

73. Kashyap MK, Kumar D, Villa R, La Clair JJ, Benner C, Sasik R, et al. Targeting the spliceosome in chronic lymphocytic leukemia with the macrolides FD895 and pladienolide-B. Haematologica. 2015;100:945-54.

74. Burkart MD, La Clair JJ, Jones BD, Mandel A, Villa R, Castro JE, Kashyap MK, et al. Anti-cancer polyketide compounds. USA: University of California; 2017.

75. Mercer TR, Dinger ME, Mattick JS. Long non-coding RNAs: insights into functions. Nat Rev Genet. 2009;10:155-9.

76. Kopp F, Mendell JT. Functional classification and experimental dissection of long noncoding RNAs. Cell. 2018;172:393-407.

77. Bartel DP. MicroRNAs: genomics, biogenesis, mechanism, and function. Cell. 2004;116:281-97.

78. Winter J, Jung S, Keller S, Gregory Rl, Diederichs S. Many roads to maturity: microRNA biogenesis pathways and their regulation. Nat Cell Biol. 2009;11: 228-34.

79. Khalife H, Skafi N, Fayyad-Kazan M, Badran B. MicroRNAs in breast cancer: new maestros defining the melody. Cancer Genet. 2019:246247:18-40. 
80. Pasquinelli AE. MicroRNAs and their targets: recognition, regulation and an emerging reciprocal relationship. Nat Rev Genet. 2012;13:271-82.

81. Wang WX, Wilfred BR, Xie K, Jennings MH, Hu YH, Stromberg AJ, et al. Individual microRNAs (miRNAs) display distinct mRNA targeting "rules". RNA Biol. 2010;7:373-80.

82. Cai $X$, Yin $Y$, Li N, Zhu D, Zhang J, Zhang CY, et al. Re-polarization of tumorassociated macrophages to pro-inflammatory M1 macrophages by microRNA-155. J Mol Cell Biol. 2012:4:341-3.

83. Wang L, Hu YY, Zhao JL, Huang F, Liang SQ, Dong L, et al. Targeted delivery of miR-99b reprograms tumor-associated macrophage phenotype leading to tumor regression. J ImmunoTher Cancer. 2020;8:e000517.

84. Medina PP, Nolde M, Slack FJ. OncomiR addiction in an in vivo model of microRNA-21-induced pre-B-cell lymphoma. Nature. 2010;467:86-90.

85. Kota J, Chivukula RR, O'Donnell KA, Wentzel EA, Montgomery CL, Hwang HW, et al. Therapeutic microRNA delivery suppresses tumorigenesis in a murine liver cancer model. Cell. 2009;137:1005-17.

86. Biamonte F, Santamaria G, Sacco A, Perrone FM, Di Cello A, Battaglia AM, et al. MicroRNA let-7g acts as tumor suppressor and predictive biomarker for chemoresistance in human epithelial ovarian cancer. Sci Rep. 2019;9(1): 5668.

87. Chirshev E, Hojo N, Bertucci A, Sanderman L, Nguyen A, Wang H, et al. Epithelial/mesenchymal heterogeneity of high-grade serous ovarian carcinoma samples correlates with miRNA let-7 levels and predicts tumor growth and metastasis. Mol Oncol. 2020;14(11):2796-28. https://doi.org/10.1 002/1878-0261.12762.

88. Connolly E, Melegari M, Landgraf P, Tchaikovskaya T, Tennant BC, Slagle BL, et al. Elevated expression of the miR-17-92 polycistron and miR-21 in hepadnavirus-associated hepatocellular carcinoma contributes to the malignant phenotype. Am J Pathol. 2008;173:856-64.

89. Cochrane DR, Howe EN, Spoelstra NS, Richer JK. Loss of miR-200c: a marker of aggressiveness and Chemoresistance in female reproductive cancers. J Oncol. 2010:821717.

90. Schickel R, Park SM, Murmann AE. Peter ME: miR-200c regulates induction of apoptosis through CD95 by targeting FAP-1. Mol Cell. 2010;38:908-15

91. Gregory PA, Bert AG, Paterson EL, Barry SC, Tsykin A, Farshid G, et al. The miR-200 family and miR-205 regulate epithelial to mesenchymal transition by targeting ZEB1 and SIP1. Nat Cell Biol. 2008;10(5):593-601.

92. Belluti S, Rigillo G, Imbriano C. Transcription factors in Cancer: when alternative splicing determines opposite cell fates. Cells. 2020;9:760.

93. C Cillo: HOX genes in human cancers. Invasion Meta 1994-1995, 14:38-49.

94. Shah N, Sukumar S. The Hox genes and their roles in oncogenesis. Nat Rev Cancer. 2010;10:361-71.

95. Lin Z, Hu Y, Lin R, Ye H. The effect of overexpression of the HOXD10 gene on the malignant proliferation, invasion, and tumor formation of pancreatic cancer cell PANC-1. Gland Surg. 2020:9:385-91.

96. Levy DE, Darnell JE Jr. Stats: transcriptional control and biological impact. Nat Rev Mol Cell Biol. 2002;3:651-62.

97. Shukla S, Jadli M, Thakur K, Shishodia G, Mahata S, Basir SF, et al. Level of phospho-STAT3 (Tyr705) correlates with copy number and physical state of human papillomavirus 16 genome in cervical precancer and cancer lesions. PLoS One. 2019;14:e0222089.

98. Aggarwal N, Yadav J, Thakur K, Bibban R, Chhokar A, Tripathi T, et al. Human papillomavirus infection in head and neck squamous cell carcinomas: transcriptional triggers and changed disease patterns. Front Cell Infect Microbiol. 2020;10:537650.

99. Bharti AC, Shishodia S, Reuben JM, Weber D, Alexanian R, Raj-Vadhan $S$, et al. Nuclear factor-kappaB and STAT3 are constitutively active in CD138+ cells derived from multiple myeloma patients, and suppression of these transcription factors leads to apoptosis. Blood. 2004;103:3175-84

100. Arshad S, Naveed M, Ullia M, Javed K, Butt A, Khawar M, et al. Targeting STAT-3 signaling pathway in cancer for development of novel drugs: advancements and challenges. Genet Mol Biol. 2020;43:e20180160.

101. Saad N, Alberio R, Johnson AD, Emes RD, Giles TC, Clarke $P$, et al. Cancer reversion with oocyte extracts is mediated by cell cycle arrest and induction of tumour dormancy. Oncotarget. 2018;9:16008-27.

102. Kazi A, Carie A, Blaskovich MA, Bucher C, Thai V, Moulder S, et al. Blockade of protein geranylgeranylation inhibits Cdk2-dependent p27Kip1 phosphorylation on Thr187 and accumulates p27Kip1 in the nucleus: implications for breast cancer therapy. Mol Cell Biol. 2009;29: 2254-63.
103. Hernandez-Hernandez A, Ray P, Litos G, Ciro M, Ottolenghi S, Beug H, et al. Acetylation and MAPK phosphorylation cooperate to regulate the degradation of active GATA-1. EMBO J. 2006;25:3264-74.

104. Borges S, Doppler H, Perez EA, Andorfer CA, Sun Z, Anastasiadis PZ, et al. Pharmacologic reversion of epigenetic silencing of the PRKD1 promoter blocks breast tumor cell invasion and metastasis. Breast Cancer Res. 2013;15:R66.

105. Lin X, Asgari K, Putzi MJ, Gage WR, Yu X, Cornblatt BS, et al. Reversal of GSTP1 CpG island hypermethylation and reactivation of pi-class glutathione S-transferase (GSTP1) expression in human prostate cancer cells by treatment with procainamide. Cancer Res. 2001;61:8611-6.

106. Allegrucci C, Rushton MD, Dixon JE, Sottile V, Shah M, Kumari R, et al. Epigenetic reprogramming of breast cancer cells with oocyte extracts. Mol Cancer. 2011:10:7.

107. Hautala LC, Pang PC, Antonopoulos A, Pasanen A, Lee CL, Chiu PCN, et al. Altered glycosylation of glycodelin in endometrial carcinoma. Lab Investig. 2020;100:1014-25.

108. Kato T, Wang Y, Yamaguchi K, Milner CM, Shineha R, Satomi S, et al. Overexpression of lysosomal-type sialidase leads to suppression of metastasis associated with reversion of malignant phenotype in murine B16 melanoma cells. Int J Cancer. 2001;92:797-804.

109. Lees DM, Reynolds LE, Pedrosa AR, Roy-Luzarraga M, Hodivala-Dilke KM: Phosphorylation of pericyte FAK-Y861 affects tumour cell apoptosis and tumour blood vessel regression. biorxiv 2020.

110. Mu X, Sultankulov B, Agarwal R, Mahjoub A, Schott T, Greco N, et al. Chick embryo extract demethylates tumor suppressor genes in osteosarcoma cells. Clin Orthop Relat Res. 2014;472:865-73.

111. Tsuchida A, Senda M, Ito A, Saito S, Kiso M, Ando T, et al. Roles of GalNACdisialyl Lactotetraosyl antigens in renal Cancer cells. Sci Rep. 2018;8:7017.

112. Furukawa K, Hamamura K, Ohkawa Y, Ohmi Y, Furukawa K. Disialyl gangliosides enhance tumor phenotypes with differential modalities. Glycoconj J. 2012;29:579-84.

113. Plummer R, Vidal L, Griffin M, Lesley M, de Bono J, Coulthard S, et al. Phase I study of MG98, an oligonucleotide antisense inhibitor of human DNA methyltransferase 1, given as a 7-day infusion in patients with advanced solid tumors. Clin Cancer Res. 2009;15:3177-83.

114. Lu H, Li G, Zhou C, Jin W, Qian X, Wang Z, et al. Regulation and role of post-translational modifications of enhancer of zeste homologue 2 in cancer development. Am J Cancer Res. 2016;6:2737-54.

115. Guha U, Chaerkady R, Marimuthu A, Patterson AS, Kashyap MK, Harsha HC, et al. Comparisons of tyrosine phosphorylated proteins in cells expressing lung cancer-specific alleles of EGFR and KRAS. Proc Natl Acad Sci U S A. 2008;105:14112-7.

116. Silvestroni A, Jewell KA, Lin WJ, Connelly JE, Ivancic MM, Tao WA, et al. Identification of serine/threonine kinase substrates in the human pathogen group B streptococcus. J Proteome Res. 2009;8:2563-74.

117. Fisher GH, Wellen SL, Klimstra D, Lenczowski JM, Tichelaar JW, Lizak MJ, et al. Induction and apoptotic regression of lung adenocarcinomas by regulation of a K-Ras transgene in the presence and absence of tumor suppressor genes. Genes Dev. 2001;15:3249-62.

118. Hingorani SR, Wang L, Multani AS, Combs C, Deramaudt TB, Hruban RH, et al. Trp53R172H and KrasG12D cooperate to promote chromosomal instability and widely metastatic pancreatic ductal adenocarcinoma in mice. Cancer Cell. 2005;7:469-83.

119. Barbhuiya MA, Kashyap MK, Puttamallesh VN, Kumar RV, Wu X, Pandey A, et al. Identification of spleen tyrosine kinase as a potential therapeutic target for esophageal squamous cell carcinoma using reverse phase protein arrays. Oncotarget. 2018;9:18422-34.

120. Wu X, Zahari MS, Ma B, Liu R, Renuse S, Sahasrabuddhe NA, et al. Global phosphotyrosine survey in triple-negative breast cancer reveals activation of multiple tyrosine kinase signaling pathways. Oncotarget. 2015;6:29143.

121. Bichi R, Shinton SA, Martin ES, Koval A, Calin GA, Cesari R, et al. Human chronic lymphocytic leukemia modeled in mouse by targeted TCL1 expression. Proc Natl Acad Sci U S A. 2002;99:6955-60.

122. Shimoni A, Marcus H, Canaan A, Ergas D, David M, Berrebi A, et al. A model for human B-chronic lymphocytic leukemia in human/mouse radiation chimera: evidence for tumor-mediated suppression of antibody production in low-stage disease. Blood. 1997;89:2210-8.

123. Dürig J, Ebeling $P$, Grabellus $F$, Sorg UR, Möllmann $M$, Schütt $P$, et al. A novel nonobese diabetic/severe combined immunodeficient xenograft model for chronic lymphocytic leukemia reflects important clinical characteristics of the disease. Cancer Res. 2007;67:8653-61. 
124. Wang R, Ferrell LD, Faouzi S, Maher JJ, Bishop JM. Activation of the met receptor by cell attachment induces and sustains hepatocellular carcinomas in transgenic mice. J Cell Biol. 2001;153(5):1023-34.

125. Xie W, Chow LT, Paterson AJ, Chin E, Kudlow JE. Conditional expression of the ErbB2 oncogene elicits reversible hyperplasia in stratified epithelia and up-regulation of TGFalpha expression in transgenic mice. Oncogene. 1999; 18:3593-607.

126. Le Pecq JB, Nguyen-Dat-Xuong, Gosse C, Paoletti C. A new antitumoral agent: 9-hydroxyellipticine. Possibility of a rational design of anticancerous drugs in the series of DNA intercalating drugs. Proc Natl Acad Sci U S A. 1974;71:5078-82.

127. Auclair C, Maksimenko A, Polard V. Reversion of malignant phenotype with 9-hydroxy ellipticine derivatives. France: vol. WO2007135538A3; 2007.

128. Spengler G, Molnar J, Viveiros M, Amaral L. Thioridazine induces apoptosis of multidrug-resistant mouse lymphoma cells transfected with the human ABCB1 and inhibits the expression of P-glycoprotein. Anticancer Res. 2011; 31:4201-5.

129. Amson R, Auclair C, André F, Karp J, Telerman A. Targeting TCTP with sertraline and Thioridazine in Cancer treatment. Results Probl Cell Differ. 2017;64:283-90.

130. Maruthur NM, Tseng E, Hutfless S, Wilson LM, Suarez-Cuervo C, Berger Z, et al. Diabetes medications as monotherapy or metformin-based combination therapy for type 2 diabetes: a systematic review and metaanalysis. Ann Intern Med. 2016;164:740-51.

131. Sachdev D, Yee D. Disrupting insulin-like growth factor signaling as a potential cancer therapy. Mol Cancer Ther. 2007;6:1-12.

132. Landman GW, Kleefstra N, van Hateren KJ, Groenier KH, Gans RO, Bilo HJ. Metformin associated with lower cancer mortality in type 2 diabetes: ZODIAC-16. Diabetes Care. 2010;33:322-6.

133. Podhorecka M, lbanez B, Dmoszyńska A. Metformin - its potential anti-cancer and anti-aging effects. Postepy Hig Med Dosw (Online). 2017;71:170-5.

134. Aiello A, Pandini G, Frasca F, Conte E, Murabito A, Sacco A, et al. Peroxisomal proliferator-activated receptor-gamma agonists induce partial reversion of epithelial-mesenchymal transition in anaplastic thyroid cancer cells. Endocrinology. 2006;147:4463-75.

135. Obach RS, Walsky RL, Venkatakrishnan K, Gaman EA, Houston JB, Tremaine LM. The utility of in vitro cytochrome P450 inhibition data in the prediction of drug-drug interactions. J Pharmacol Exp Ther. 2006;316:336-48.

136. Irarrázaval O ME, Gaete G L. Elección del mejor antidepresivo en pacientes con cáncer de mama en tratamiento con tamoxifeno: revisión de la evidencia básica y clínica [Antidepressants agents in breast cancer patients using tamoxifen: review of basic and clinical evidence]. Rev Med Chil. 2016; 144:1326.

137. Maira SM, Stauffer F, Schnell C, García-Echeverría C. PI3K inhibitors for cancer treatment: where do we stand? Biochem Soc Trans. 2009;37:265-72.

138. Peng X, Zhou J, Li B, Zhang T, Zuo Y, Gu X. Notch1 and PI3K/Akt signaling blockers DAPT and LY294002 coordinately inhibit metastasis of gastric cancer through mutual enhancement. Cancer Chemother Pharmacol. 2020; 85(2):309-20.

139. He K, Yu X, Wang X, Tang L, Cao Y, Xia J, Cheng J. Baicalein and Ly294002 induces liver cancer cells apoptosis via regulating phosphatidyl inositol 3kinase/Akt signaling pathway. J Cancer Res Ther. 2018;14:S519-25.

140. Sandal T, Valyi-Nagy K, Spencer VA, Folberg R, Bissell MJ, Maniotis AJ. Epigenetic reversion of breast carcinoma phenotype is accompanied by changes in DNA sequestration as measured by Alul restriction enzyme. Am J Pathol. 2007;170(5):1739-49.

141. Zhang D, Hu Q, Liu X, Ji Y, Chao HP, Liu Y, et al. Intron retention is a hallmark and spliceosome represents a therapeutic vulnerability in aggressive prostate cancer. Nat Commun. 2020;11:2089.

142. D'Anselmi F, Masiello MG, Cucina A, Proietti S, Dinicola S, Pasqualato A, et al. Microenvironment promotes tumor cell reprogramming in human breast cancer cell lines. PLoS One. 2013;8:e83770.

143. Willhauck MJ, Mirancea N, Vosseler S, Pavesio A, Boukamp P, Mueller MM, et al. Reversion of tumor phenotype in surface transplants of skin SCC cells by scaffold-induced stroma modulation. Carcinogenesis. 2007;28:595-610.

144. Fischinger PJ, Nomura S, Peebles PT, Haapala DK, Bassin RH. Reversion of murine sarcoma virus transformed mouse cells: variants without a rescuable sarcoma virus. Science. 1972;176:1033-5.

145. Huang ME, Ye YC, Chen SR, Chai JR, Lu JX, Zhoa L, et al. Use of all-trans retinoic acid in the treatment of acute promyelocytic leukemia. Blood. 1988; 72:567-72.
146. Zhou GB, Zhang J, Wang ZY, Chen SJ, Chen Z. Treatment of acute promyelocytic leukaemia with all-trans retinoic acid and arsenic trioxide: a paradigm of synergistic molecular targeting therapy. Philos Trans R Soc Lond Ser B Biol Sci. 2007:362:959-71.

147. Ewald D, Li M, Efrat S, Auer G, Wall RJ, Furth PA, et al. Time-sensitive reversal of hyperplasia in transgenic mice expressing SV40 T antigen. Science. 1996; 273:1384-6.

148. Huettner CS, Zhang P, Van Etten RA, Tenen DG. Reversibility of acute B-cell leukaemia induced by BCR-ABL1. Nat Genet. 2000;24:57-60.

149. Rabinowitz Z, Sachs L. Reversion of properties in cells transformed by polyoma virus. Nature. 1968;220:1203-6.

150. Sachs $L$. Control of normal cell differentiation and the phenotypic reversion of malignancy in myeloid leukaemia. Nature. 1978;274(5671):535-9.

151. Telerman A, Tuynder M, Dupressoir T, Robaye B, Sigaux F, Shaulian E, et al. A model for tumor suppression using H-1 parvovirus. Proc Natl Acad Sci U S A. $1993 ; 90: 8702-6$

152. Becceneri AB, Popolin CP, Plutin AM, Maistro EL, Castellano EE, Batista AA, et al. Three-dimensional cell culture models for metallodrug testing: induction of apoptosis and phenotypic reversion of breast cancer cells by the trans-[Ru (PPh3)2(N,N-dimethyl-N-thiophenylthioureato-k2O,S)(bipy)]PF6 complex. J Inorg Biochem. 2020;7:2909-19.

153. Mi KXZ. CD44+/CD24- breast cancer cells exhibit phenotypic reversion in three-dimensional self-assembling peptide RADA16 nanofiber scaffold. Int 」 Nanomedicine. 2015;10:3043-53.

154. Weaver VM, Petersen OW, Wang F, Larabell CA, Briand P, Damsky C, et al, Reversion of the malignant phenotype of human breast cells in threedimensional culture and in vivo by integrin blocking antibodies. J Cell Biol. 1997;137:231-45.

155. Wang F, Weaver VM, Petersen OW, Larabell CA, Dedhar S, Briand P, et al. Reciprocal interactions between beta1-integrin and epidermal growth factor receptor in three-dimensional basement membrane breast cultures: a different perspective in epithelial biology. Proc Natl Acad Sci U S A. 1998;95:14821-6.

156. Romer AM, Luhr I, Klein A, Friedl A, Sebens S, Rosel F, et al. Normal mammary fibroblasts induce reversion of the malignant phenotype in human primary breast cancer. Anticancer Res. 2013;33:1525-36.

157. Reginato MJ, Mills KR, Becker EB, Lynch DK, Bonni A, Muthuswamy SK, et al. Bim regulation of lumen formation in cultured mammary epithelial acini is targeted by oncogenes. Mol Cell Biol. 2005;25:4591-601.

158. Krause S, Maffini MV, Soto AM, Sonnenschein C. The microenvironment determines the breast cancer cells' phenotype: organization of MCF7 cells in 3D cultures. BMC Cancer. 2010;10:263.

159. Kenny PA, Lee GY, Myers CA, Neve RM, Semeiks JR, Spellman PT, et al. The morphologies of breast cancer cell lines in three-dimensional assays correlate with their profiles of gene expression. Mol Oncol. 2007;1:84-96.

160. Noda M, Kitayama H, Matsuzaki T, Sugimoto Y, Okayama H, Bassin RH, et al. Detection of genes with a potential for suppressing the transformed phenotype associated with activated ras genes. Proc Natl Acad Sci U S A. 1989;86:162-6.

161. Mitsuzuka K, Handa K, Satoh M, Arai Y, Hakomori S. A specific microdomain ("glycosynapse 3") controls phenotypic conversion and reversion of bladder cancer cells through GM3-mediated interaction of alpha3beta1 integrin with CD9. J Biol Chem. 2005;280:35545-53.

162. Miura Y, Kainuma M, Jiang H, Velasco H, Vogt PK, Hakomori S. Reversion of the Jun-induced oncogenic phenotype by enhanced synthesis of sialosyllactosylceramide (GM3 ganglioside). Proc Natl Acad Sci U S A. 2004; 101:16204-9.

163. Gaj T, Gersbach CA, Barbas CF 3rd. ZFN, TALEN, and CRISPR/Cas-based methods for genome engineering. Trends Biotechnol. 2013;31:397-405.

164. Wang H, Yang H, Shivalila CS, Dawlaty MM, Cheng AW, Zhang F, et al. Onestep generation of mice carrying mutations in multiple genes by CRISPR/ Cas-mediated genome engineering. Cell. 2013;153(4):910-8.

165. Jiang F, Doudna JA. CRISPR-Cas9 structures and mechanisms. Annu Rev Biophys. 2017:46:505-29.

166. Dana C. Genome engineering with zinc-finger nucleases. Genetics. 2011;188: $773-82$.

167. Yan W, Smith C, Cheng L. Expanded activity of dimer nucleases by combining ZFN and TALEN for genome editing. Sci Rep. 2013;3:2376.

168. Windham J Sharma S, Kashyap MK, Rustgi S. CRISPR/Cas12a (Cpf1) and its role in plant genome editing. Springer Nature (in press): In RNA-based technologies for functional genomics in plants. Edited by G. Tang ST, X. Tang, D. Singh (Eds.). 2021 
169. Amson R, Pece S, Lespagnol A, Vyas R, Mazzarol G, Tosoni D, et al. Reciprocal repression between P53 and TCTP. Nat Med. 2011;18:91-9.

170. Dawson PJ, Wolman SR, Tait L, Heppner GH, Miller FR. MCF10AT: a model for the evolution of cancer from proliferative breast disease. Am J Pathol. 1996;148:313-9.

171. Shaheed SU, Rustogi N, Scally A, Wilson J, Thygesen H, Loizidou MA, et al. Identification of stage-specific breast markers using quantitative proteomics. J Proteome Res. 2013;12:5696-708.

172. Malek E, Driscoll JJ. High throughput chemical library screening identifies a novel p110- $\delta$ inhibitor that potentiates the anti-myeloma effect of bortezomib. Oncotarget. 2016;7:38523-38.

173. Zheng X, Turkowski K, Mora J, Brune B, Seeger W, Weigert A, et al. Redirecting tumor-associated macrophages to become tumoricidal effectors as a novel strategy for cancer therapy. Oncotarget. 2017;8(29):48436-52.

174. Brabletz S, Brabletz T. The ZEB/miR-200 feedback loop--a motor of cellular plasticity in development and cancer? EMBO Rep. 2010;11:670-7.

\section{Publisher's Note}

Springer Nature remains neutral with regard to jurisdictional claims in published maps and institutional affiliations.

Ready to submit your research? Choose BMC and benefit from:

- fast, convenient online submission

- thorough peer review by experienced researchers in your field

- rapid publication on acceptance

- support for research data, including large and complex data types

- gold Open Access which fosters wider collaboration and increased citations

- maximum visibility for your research: over $100 \mathrm{M}$ website views per year

At BMC, research is always in progress.

Learn more biomedcentral.com/submissions 